\title{
Fiscal unions redux
}

\author{
Patrick J. Kehoe ${ }^{1,2,3,4}$ - Elena Pastorino ${ }^{1,3,4}$
}

Received: 28 November 2014 / Accepted: 9 November 2016 / Published online: 2 February 2017 C The Author(s) 2017. This article is published with open access at Springerlink.com

\begin{abstract}
Before the advent of sophisticated international financial markets, a widely accepted belief was that within a monetary union, a union-wide authority orchestrating fiscal transfers between countries is necessary to provide adequate insurance against country-specific economic fluctuations. A natural question is then: Do sophisticated international financial markets obviate the need for such an active union-wide authority? We argue that they do. Specifically, we show that in a benchmark economy with no international financial markets, an activist union-wide authority is necessary to achieve desirable outcomes. With sophisticated international financial markets, however, such an authority is unnecessary if its only goal is to provide cross-country insurance. Since restricting the set of policy instruments available to member countries does not create a fiscal externality across them, this result holds in a wide variety of settings. Finally, we establish that an activist union-wide authority concerned just with providing insurance to member countries is optimal only when individual countries are either unable or unwilling to pursue desirable policies.
\end{abstract}

\footnotetext{
We thank the editor, the referees, Eugenia Gonzalez Aguado, Zefeng Chen, and Sergio Salgado Ibanez for helpful comments. We are grateful to Joan Gieseke for editorial assistance. For research support, we thank the ADEMU project, which is sponsored by the European Commission Horizon 2020 European Union Funding for Research and Innovation, Grant Agreement No. 649396, as well as the National Science Foundation. The views expressed herein are those of the authors and not necessarily those of the Federal Reserve Bank of Minneapolis or the Federal Reserve System.
}

$凶$ Patrick J. Kehoe

patrickjameskehoe@gmail.com

1 University of Minnesota, Minneapolis, MN, USA

2 University College London, London, UK

3 Stanford University, Stanford, CA, USA

4 Federal Reserve Bank of Minneapolis, Minneapolis, MN, USA 
Keywords Cross-country externalities · Cross-country insurance · Cross-country transfers · Fiscal externalities · International financial markets · International transfers $\cdot$ Optimal currency area

\section{JEL Classification E60 $\cdot$ E61 $\cdot$ F33 $\cdot$ F36 $\cdot$ F38 $\cdot$ F42 $\cdot$ F45 $\cdot$ G15 $\cdot$ G28}

A monetary union sets union-wide monetary policy in the hope of achieving desirable outcomes. When a monetary union is established, a classic question arises: How should the fiscal policies of member countries be coordinated? In particular, is it desirable to establish a union-wide authority to coordinate the fiscal policies of member countries as well as to implement international fiscal transfers between them? Amid the recent debate about the desirability of greater fiscal integration within the European Union, such a question has regained center stage.

Before the advent of sophisticated international financial markets, a widely accepted belief was that within a monetary union, a union-wide authority orchestrating fiscal transfers is desirable to provide adequate insurance against country-specific macroeconomic shocks. In this paper, we examine whether the need for such an authority to provide cross-country insurance has decreased as international financial markets have become more developed. In short: Can international financial markets substitute for a fiscal union?

One view, associated with Mundell (1973), is that sophisticated international financial markets are sufficient to provide insurance against country-specific economic fluctuations. Mundell illustrated this point using a simple example in which the world consists of two islands: Capricorn, which is south of the equator and produces its crops in the fall, and Cancer, which is north of the equator and produces its crops in the spring. Both countries are subject to random fluctuations in their crop output, and goods can be stored only for six months. Mundell explains how, even with labor immobile across countries, well-developed insurance markets can achieve the same outcomes that would be achieved if labor were perfectly mobile and individuals migrated every six months to the island in which crops can be grown. In short, in Mundell's view, international financial markets can provide all the necessary cross-country insurance, thereby obviating the need for a fiscal union to implement any transfer.

An alternative view, associated with Kenen (1969), is that transfers between regions of a monetary union are critical to its functioning. Specifically, Kenen argues that in a currency union, "the domain of fiscal policy ought to coincide with the currency area" (Kenen 1969, p. 46). In this essay, Kenen also explains how a well-functioning fiscal union entails large-scale transfers between countries in the face of country-specific economic fluctuations.

In this paper, we argue that the key difference between Mundell's and Kenen's views of international transfers can be traced back to their distinct ideas of what a union-wide authority should accomplish. From Mundell's point of view, the role of a union-wide authority is simply to provide insurance to member countries, whereas from Kenen's point of view, the role of such an authority also entails performing an exante redistribution of wealth, say, from richer countries to poorer countries in a union. Our main result is that under Mundell's view, the advent of sophisticated financial 
markets obviates the need for any such authority to provide international transfers, whereas under Kenen's view, such a union-wide authority should play an active role even in the presence of sophisticated financial markets.

We consider several settings for policy. In our benchmark setting, member countries' policies are rich enough that countries can correct all their domestic distortions. We then investigate a restricted policy setting in which member countries' policies are symmetrically constrained in a way that prevents them from resolving all their domestic distortions. In both settings, we find support for Mundell's view: if the role of a union-wide authority is simply to provide insurance and its only instruments are transfers between countries, then there is still no need for it to play an active role. In particular, restrictions on member countries' policies do not create a fiscal externality, whereby each country adopts a policy that is optimal for that country but is suboptimal for the union as a whole.

We derive our result under five main assumptions: (i) all countries are small in the relevant sense, (ii) the union-wide authority and member countries can commit to their policies, (iii) the union-wide authority has no advantage over national governments in its choice of policy instruments, (iv) the government of each country maximizes the welfare of its citizens, and (v) the union-wide authority maximizes a Pareto-weighted sum of countries' utilities, with weights that ensure that the union-wide authority is only concerned with providing insurance to member countries rather than with redistributing wealth. If we dispense with any of these assumptions, a role for an active union-wide authority emerges.

We illustrate this point by analyzing three settings that relax some of these assumptions. First, we allow the union-wide authority to have access to instruments that some of the national governments do not have available. In particular, we envision a more powerful union-wide authority that, in addition to its ability to impose international transfers, can levy portfolio taxes on each member country's international financial transactions. This expansive view of a union-wide authority's powers goes well beyond the limited role envisioned for it by Mundell, but is consistent with the role envisioned for it by Kenen. In this setting, when the policies of member countries are restricted in various ways, it is typically optimal for the union-wide authority to intervene by levying portfolio taxes on the countries facing policy restrictions. The rationale for this intervention, however, is not specifically to improve cross-country insurance, but rather to help ameliorate domestic distortions in countries that are unable to do so on their own.

The results from this first setting might lead one to conjecture that the need to levy portfolio taxes is intimately connected to the restrictions on policy that arise from countries belonging to a monetary union. Our second setting shows that this conjecture is incorrect: if national governments face constraints on their policies, then the unionwide authority typically has an incentive to intervene and impose portfolio taxes even when countries have flexible exchange rates.

In the settings considered so far, equilibrium outcomes, except for international transfers, are invariant to whether a given policy is delegated to national governments or to the union-wide authority. Our third setting is one in which this irrelevance of delegation of authority result no longer holds. In this case, we allow for self-interested governments that maximize objective functions that are different from those of their 
citizens. We also allow governments to choose government spending that only benefits themselves. We think of this environment as capturing the idea that for a whole host of reasons, including political ones, some governments are unwilling to pursue policies that are most desirable for their citizens. We show that in this scenario, it is better to delegate the power to levy portfolio taxes to a union-wide authority rather than to national governments.

These three settings generate a role for an active union-wide authority. All of them, however, clearly have a paternalistic flavor: a responsible and powerful union-wide authority should provide remedial help to member countries, that is, should intervene only when member countries' governments are either unable or unwilling to pursue desirable policies.

In our analysis, we closely follow Farhi and Werning (2013), henceforth FW, by considering a simple one-period economy with a continuum of countries, each of which produces traded and nontraded goods. The nontraded goods sector consists of a continuum of monopolistically competitive intermediate goods firms that produce differentiated products. The prices of these firms are sticky in that they must be set before the realization of preference and productivity shocks. The traded goods sector is competitive and has flexible prices. This economy builds on Obstfeld and Rogoff (1995) and is a special case of Gali and Monacelli (2005, 2008).

Even though we purposely adopt the setup of FW in our analysis, we arrive at very different conclusions. The key difference between our work and that of FW is that we build in, as part of Mundell's view, the idea that the goal of a union-wide authority is simply to provide insurance rather than to redistribute ex-ante wealth, whereas FW presume that a union-wide authority is also concerned with redistribution over and above insurance.

Our benchmark fiscal policies grant each government a payroll tax on labor income, excise taxes on nontraded goods, portfolio taxes, and domestic transfers, whereas restricted fiscal policies disallow the use of nontraded goods taxes. This restriction adds an extra constraint on each government's problem, which one might conjecture could give rise to fiscal externalities. The fiscal union features three tiers of decision makers. At the top tier, a union-wide authority chooses international transfers between countries to maximize a weighted sum of the welfare of consumers in each country. At the middle tier, the governments of all countries, taking as given the international transfers set by the union-wide authority, noncooperatively choose their countries' fiscal policies, or simply national policies, in order to maximize the welfare of the consumers of their countries. At the bottom tier, consumers and firms in each country, taking as given both the policies of the union-wide authority and the national governments, make production and consumption decisions.

We begin by studying the need for a fiscal union when each national government has access to the benchmark fiscal policies. We start with an incomplete market setting that captures in a stark way the idea that before the modern era of international financial markets, cross-country insurance could only be provided through direct cross-country transfers. As both Mundell and Kenen agree, in such an era there is a clear need for an active union-wide fiscal authority.

We then consider a setting with complete international financial markets. We think of this complete market setting as capturing the idea that, in the modern era of sophis- 
ticated international financial markets, countries can rely on these markets to obtain cross-country insurance. We show that with complete markets, a union-wide fiscal authority is unnecessary if and only if this authority is concerned solely with providing insurance to member countries. That is, under Mundell's view of the role of a fiscal authority, complete markets ensure that the optimal amount of insurance is obtained, whereas under Kenen's view, a fiscal authority is still needed to accomplish any ex-ante wealth redistribution between member countries.

We then investigate whether, once we restrict the fiscal instruments of national governments, a fiscal externality arises across countries that necessitates an activist union-wide authority. That is, we repeat our previous exercise, now with restricted policies, to determine whether the policies that governments choose to pursue are inefficient from the viewpoint of the union as a whole. Our key result is that no fiscal externality arises in this case: even though national governments are unable to correct all their domestic distortions, they still pursue policies that are optimal for the union. Thus, even here, we find that a union-wide fiscal authority is unnecessary with complete markets if and only if this authority is concerned solely with insurance among countries in the union.

We then turn to identifying circumstances under which it is optimal for a union-wide authority uninterested in redistribution to pursue an activist role in fiscal policy. For simplicity, we consider a setting in which one group of countries in the union, called the North, optimally sets traditional fiscal instruments, that is, payroll and nontraded goods taxes, but the other group, called the South, is unable (or unwilling) to use nontraded goods taxes. We think of this setup as capturing the idea that the South has poorly functioning governments. We equip the union-wide authority with portfolio taxes that it can levy on any country in the union, and show that it is optimal for the union-wide authority to impose portfolio taxes only on Southern countries. By doing so, the authority raises the welfare of all countries in the union by partially offsetting the distortions that the Southern countries are unable to correct on their own.

Of course, if in this setting we allowed countries to have flexible exchange rates, they could use their domestic monetary policies to offset country-specific shocks, and there would be no need for an activist union-wide authority. This result may lead one to think that, more generally, the only reason why the union-wide authority would take an active role in policy is that countries cannot use their domestic monetary policies to offset country-specific shocks. To show that this reasoning is incorrect, we consider a fiscal union with flexible exchange rates but assume that Northern countries have access only to portfolio taxes, whereas Southern countries again have imperfectly functioning governments in that they are unable to levy any taxes. The union-wide authority can levy portfolio taxes on any country in the union. We show that in this case, the union-wide authority plays an active role by levying portfolio taxes on Southern countries. As before, though, doing so does not correct any macroeconomic externality; instead, it simply helps Southern countries ameliorate their domestic distortions.

So far, we have assumed that national governments are benevolent in that they maximize the welfare of their citizens. Under this assumption, an irrelevance of delegation of authority result holds: the equilibrium is unchanged if any of the payroll taxes, nontraded goods taxes, or portfolio taxes are delegated to the national governments or the union-wide authority. Our last economy shows that if, instead, national governments 
pursue their own self-interests, then the union as a whole typically has an incentive to delegate powers, such as portfolio taxes, to a benevolent union-wide authority rather than to the national governments.

Our analysis implies that even when governments have only restricted fiscal instruments available, no fiscal externalities arise. A key feature of our model behind this finding is that governments have the power to commit to their fiscal policies once and for all. By doing so, we abstract from the fiscal externalities that result from lack of commitment when national fiscal policies are set noncooperatively. These issues are the focus of the work of Chari and Kehoe $(2007,2008)$ and have recently been revisited by Aguiar et al. (2013), who draw the same conclusions as Chari and Kehoe (2007, 2008) do.

\section{A currency-fiscal union with incomplete financial markets}

Here we set up a model of a joint currency-fiscal union with incomplete international financial markets. This model is meant to capture a setting in which international financial markets cannot provide adequate insurance across countries against countryspecific macroeconomic shocks. For simplicity, we make the extreme assumption that no international financial markets exist.

Throughout, we distinguish between transfers motivated by insurance reasons and transfers motivated by redistributive reasons. To this end, we are interested in transfers that respect private ownership, that is, transfers that are optimal when the union-wide fiscal authority uses a Pareto weight for each country that, at the appropriately defined shadow prices, does not involve an ex-ante redistribution of wealth from one country to another, say, from ex-ante richer countries to ex-ante poorer countries.

The timing of the economy involves three stages, which reflect the three-tiered structure of decision making discussed earlier. At the first stage, the union-wide authority moves and sets international transfers. At the second stage, taking as given the decisions of the union-wide authority, national governments set their national fiscal policies noncooperatively. At the third stage, taking as given the policies set in the previous stages, consumers and firms in each country make their production and consumption decisions. It is convenient to both set up and solve for the overall equilibrium, referred to as the world equilibrium, by working backwards from the end of the period. We therefore start with the bottom tier.

\subsection{Bottom tier: competitive equilibrium}

We start by laying out the economy and defining a competitive equilibrium, given the union-wide and national policies chosen at higher tiers.

The economy lasts one period, features a continuum of countries $i \in I=[0,1]$ that belong to a currency union, and is adopted from FW. The uncertainty in the economy is represented by a finite set of states $s \in S$ with $\mu(s)$ denoting the probability of state $s$. This uncertainty affects preferences and technology. Each consumer in country $i$ has preferences over nontraded goods, $C_{N}^{i}(s)$, traded goods, $C_{T}^{i}(s)$, and labor, $L^{i}(s)$, given by 


$$
\sum_{s} \mu(s) U^{i}\left(C_{N}^{i}(s), C_{T}^{i}(s), L^{i}(s), s\right) .
$$

Trade of state-contingent assets in domestic asset markets between consumers in country $i$ takes place before the state $s$ is realized, subject to the asset market constraint

$$
\sum_{s} Q^{i}(s) D^{i}(s) \leq 0
$$

In each state $s$, a consumer also faces a budget constraint given by

$$
\begin{aligned}
& {\left[1+\tau_{N}^{i}(s)\right] P_{N}^{i} C_{N}^{i}(s)+P_{T}(s) C_{T}^{i}(s) \leq W^{i}(s) L^{i}(s)} \\
& \quad+P_{T}(s)\left[Y_{T}^{i}(s)+T^{i}(s)+T_{I}^{i}(s)\right]+\Pi^{i}(s)+\left[1-\tau_{D}^{i}(s)\right] D^{i}(s) .
\end{aligned}
$$

All prices are expressed in units of a common currency, say, euros. Here $Q^{i}(s)$ is the price at the beginning of the period for the delivery of one euro in state $s, P_{N}^{i}(s)$ is the country-specific price of nontraded goods, and $P_{T}(s)$ is the union-wide price of traded goods. Consumers in country $i$ have endowments of traded goods, $Y_{T}^{i}(s)$, elastically supply labor, $L^{i}(s)$, to produce nontraded goods at a nominal wage of $W^{i}(s)$, and receive nominal profits of $\Pi^{i}(s)$ from the ownership of nontraded goods firms. Consumers take as given the policies of their national governments, namely, the tax rate on the purchases of nontraded goods in state $s, \tau_{N}^{i}(s)$, the tax rate on domestic assets, $\tau_{D}^{i}(s)$, and the domestic transfers, $T^{i}(s)$, as well as the policies of the union-wide fiscal authority, namely, the international transfers, $T_{I}^{i}(s)$. Throughout, domestic and international transfers are in units of traded goods.

The first-order conditions for the consumer's problem imply that for all states $s$,

$$
\begin{aligned}
& \rho^{i}=\mu(s) \frac{U_{T}^{i}(s)\left[1-\tau_{D}^{i}(s)\right]}{P_{T}(s) Q^{i}(s)}, \\
& \frac{U_{T}^{i}(s)}{P_{T}(s)}=\frac{U_{N}^{i}(s)}{\left[1+\tau_{N}^{i}(s)\right] P_{N}^{i}}, \\
& -\frac{U_{L}^{i}(s)}{U_{T}^{i}(s)}=\frac{W^{i}(s)}{P_{T}(s)},
\end{aligned}
$$

where $\rho^{i}$ is the multiplier on the asset market constraint (2). Here all asset trade is domestic in that

$$
D^{i}(s)=0 \text { for all } i \text { and } s .
$$

In each country $i$, competitive nontraded final goods firms buy differentiated varieties of nontraded goods from intermediate producers, combine them into final goods, and sell them to consumers in country $i$. These firms solve

$$
\max _{\left\{C_{N}^{i, j}(s)\right\}}\left\{P_{N}^{i} C_{N}^{i}(s)-\int_{0}^{1} P_{N}^{i, j} C_{N}^{i, j}(s) \mathrm{d} j\right\},
$$


subject to $C_{N}^{i}(s)=\left[\int_{0}^{1} C_{N}^{i, j}(s)^{\frac{\varepsilon-1}{\varepsilon}} \mathrm{d} j\right]^{\frac{\varepsilon}{\varepsilon-1}}$, where $\varepsilon$ is the elasticity of substitution among varieties, $P_{N}^{i}$ is the price of the aggregate bundle of goods, and $P_{N}^{i, j}$ and $C_{N}^{i, j}(s)$ are the price and quantity of variety $j$ in country $i$ at state $s$. This problem generates a downward-sloping demand curve for each variety $j$,

$$
C_{N}^{i, j}(s)=\left(\frac{P_{N}^{i, j}}{P_{N}^{i}}\right)^{-\varepsilon} C_{N}^{i}(s) .
$$

The intermediate goods producers are monopolistically competitive and have sticky prices in that they set their prices before the realization of the state, $s$. The producer of variety $j$ in country $i$ produces goods with the technology $C_{N}^{i, j}(s)=A^{i}(s) L^{i, j}(s)$ and charges the price $P_{N}^{i, j}$, where $L^{i, j}(s)$ is the amount of labor employed by this producer. The profits in state $s$ of such an intermediate goods producer are

$$
\Pi^{i, j}(s)=P_{N}^{i, j} C_{N}^{i, j}(s)-\left(1+\tau_{L}^{i}\right) W^{i}(s) L^{i, j}(s),
$$

where $\tau_{L}^{i}$ is a payroll tax on the labor hired by these firms. The price is chosen to maximize the value of profits,

$$
\max _{P_{N}^{i, j}}\left\{\sum_{s} Q^{i}(s)\left[P_{N}^{i, j}-\left(1+\tau_{L}^{i}\right) \frac{W^{i}(s)}{A^{i}(s)}\right]\left(\frac{P_{N}^{i, j}}{P_{N}^{i}}\right)^{-\varepsilon} C_{N}^{i}(s)\right\},
$$

where we have substituted the production technology and the demand function in (9) into the expression for profits in (10). The resulting optimal price is given by

$$
P_{N}^{i, j}=\left(1+\tau_{L}^{i}\right) \frac{\varepsilon}{\varepsilon-1} \frac{\sum_{s} Q^{i}(s) \frac{W^{i}(s)}{A^{i}(s)} C_{N}^{i}(s)}{\sum_{s} Q^{i}(s) C_{N}^{i}(s)},
$$

which is a markup over a weighted average of the marginal cost of labor across states. Notice that the price of each variety $j$ in country $i$ is the same and equal to the right side of (12) and, thus, so are the choices for output and labor, that is, $P_{N}^{i, j}=P_{N}^{i, j^{\prime}}$, $C_{N}^{i, j}(s)=C_{N}^{i, j^{\prime}}(s)$, and $L^{i, j}(s)=L^{i, j^{\prime}}(s)$ for all $j$ and $j^{\prime}$. Clearly, the price of each variety $j$ thus equals the aggregate price index, $P_{N}^{i}$, the output of each variety equals the aggregate quantity of nontraded goods, $C_{N}^{i}(s)$, and the labor hired by each producer $j$ in country $i$ is independent of $j$ and can be written as $L^{i}(s)$.

Consider now the national policies of country $i$. The policies of country $i$ 's government are summarized by $\pi^{i}=\left\{\pi^{i}(s)\right\}$, where $\pi^{i}(s)=\left(\tau_{L}^{i}, \tau_{N}^{i}(s), \tau_{D}^{i}(s), T^{i}(s)\right)$. For each $s$, the government budget constraint requires that domestic transfers equal domestic tax revenues,

$$
P_{T}(s) T^{i}(s)=\tau_{L}^{i} W^{i}(s) L^{i}(s)+\tau_{N}^{i}(s) P_{N}^{i} C_{N}^{i}(s)+\tau_{D}^{i}(s) D^{i}(s)
$$


The government collects revenues from the payroll tax, the tax on the consumption of nontraded goods, and the portfolio tax, and rebates these revenues to its consumers in a lump-sum fashion.

The policies of the union-wide authority are international transfers, $T_{I}^{i}=\left\{T_{I}^{i}(s)\right\}$. The budget constraint of this authority specifies that international transfers across countries sum to zero in each state $s$,

$$
\int_{i} T_{I}^{i}(s) \mathrm{d} i=0 .
$$

Notice that here the union-wide authority transfers resources directly to consumers rather than to national governments.

Formally, let $X=\left\{X^{i}\right\}$, with $X^{i}=\left\{X^{i}(s)\right\}$ and $X^{i}(s)=\left(C_{T}^{i}(s), C_{N}^{i}(s), L^{i}(s)\right.$, $D^{i}(s)$ ), denote the allocations in country $i, P=\left\{P^{i}\right\}$, with $P^{i}=\left\{P^{i}(s)\right\}$ and $P^{i}(s)=$ $\left(P_{N}^{i}, W^{i}(s)\right)$, and $Q=\left\{Q^{i}\right\}$, with $Q^{i}=\left\{Q^{i}(s)\right\}$, denote the domestic prices in country $i$, and $\pi=\left\{\pi^{i}\right\}$ denote national policies. Let $P_{T}=\left\{P_{T}(s)\right\}$ denote the world prices of traded goods, and let $T_{I}=\left\{T_{I}^{i}\right\}$, with $T_{I}^{i}=\left\{T_{I}^{i}(s)\right\}$, denote the international transfers to country $i$.

Given the policies of the union-wide authority, $\left\{T_{I}^{i}\right\}$, and the national policies, $\left\{\pi^{i}\right\}$, a competitive equilibrium with incomplete markets consists of world prices, $P_{T}$, together with allocations, $\left\{X^{i}\right\}$, and domestic prices, $\left\{P^{i}\right\}$ and $\left\{Q^{i}\right\}$, for each country $i$ such that: (i) consumer maximization in each country $i$ holds, (ii) profit maximization for both final goods firms and intermediate goods firms in each country $i$ holds, (iii) the national policy, $\pi^{i}$, satisfies the government budget constraint of each country $i$, (13), (iv) the union-wide policies, $\left\{T_{I}^{i}\right\}$, satisfy the budget constraint of the union-wide authority, (14), (v) all asset trade is domestic in the sense that (7) holds, and (vi) the nontraded goods market-clearing condition holds for each country $i$,

$$
C_{N}^{i}(s)=A^{i}(s) L^{i}(s) \text { for all } s,
$$

and the world traded goods market-clearing condition holds,

$$
\int_{i} C_{T}^{i}(s) \mathrm{d} i=\int_{i} Y_{T}^{i}(s) \mathrm{d} i \text { for all } s .
$$

We will show that in an equilibrium with incomplete markets, the conditions above imply a country $i$ market-clearing condition for traded goods,

$$
C_{T}^{i}(s)=Y_{T}^{i}(s)+T_{I}^{i}(s) \text { for all } s
$$

The following lemma characterizes the set of allocations that can be implemented in such an equilibrium.

Lemma 1 The allocations in a competitive equilibrium with incomplete markets satisfy the nontraded and world traded goods market-clearing conditions, namely, (15) 
and (16). Moreover, given any allocations that satisfy these constraints, we can construct prices and policies for each country that, together with the given allocations, constitute a competitive equilibrium with incomplete markets.

Proof: For necessity, by definition of an equilibrium, the allocations satisfy nontraded and traded goods market clearing. For sufficiency, given some allocations, we construct prices, policies, and asset holdings as follows. Clearly, there is one degree of nominal indeterminacy in the construction of nominal goods prices, which we resolve by setting $P_{T}\left(s_{0}\right)=1$ for some particular state $s_{0}$. To see there is also some indeterminacy in the setting of nontraded goods taxes, $\tau_{N}^{i}(s)$, note that (5) implies

$$
\frac{U_{T}^{i}(s) / U_{N}^{i}(s)}{U_{T}^{i}\left(s_{0}\right) / U_{N}^{i}\left(s_{0}\right)}=\frac{P_{T}(s)\left[1+\tau_{N}^{i}\left(s_{0}\right)\right]}{1+\tau_{N}^{i}(s)} .
$$

We uniquely pin down $P_{T}(s)$ by picking a country, say, $i=0$, and setting $\tau_{N}^{0}(s)=0$ for all $s$. Doing so gives

$$
P_{T}(s)=\frac{U_{T}^{0}(s) / U_{N}^{0}(s)}{U_{T}^{0}\left(s_{0}\right) / U_{N}^{0}\left(s_{0}\right)} .
$$

Given $P_{T}(s)$, however, (18) makes clear that for each country $i \neq 0$, there is still one degree of indeterminacy in nontraded goods taxes. To resolve this indeterminacy, we pick a state, say, $s_{0}$, and set $\tau_{N}^{i}\left(s_{0}\right)=0$ for all $i$. Then, using $P_{T}\left(s_{0}\right)=1$ and $\tau_{N}^{i}\left(s_{0}\right)=0$ for all $i$, from (5) we obtain

$$
P_{N}^{i}=\frac{U_{N}^{i}\left(s_{0}\right)}{U_{T}^{i}\left(s_{0}\right)} .
$$

Then, using $\tau_{N}^{i}\left(s_{0}\right)=0$ and (18) gives that the tax on nontraded goods for a country $i \neq 0$ is given by

$$
1+\tau_{N}^{i}(s)=\frac{U_{T}^{i}\left(s_{0}\right) / U_{N}^{i}\left(s_{0}\right)}{U_{T}^{i}(s) / U_{N}^{i}(s)} P_{T}(s),
$$

and from (6) wages are given by

$$
W^{i}(s)=-\frac{U_{L}^{i}(s)}{U_{T}^{i}(s)} P_{T}(s),
$$

where $P_{T}(s)$ is given by (19).

There is also one degree of nominal indeterminacy in asset prices. We resolve this indeterminacy by setting $Q^{i}\left(s_{0}\right)=1$. There is clearly also a joint indeterminacy in $Q^{i}(s)$ and $\tau_{D}^{i}(s)$. We resolve it by letting $Q^{i}(s)=Q(s)$ for all $i$ and $s$, setting $\tau_{D}^{0}(s)=0$ for all $s$, and $\tau_{D}^{i}\left(s_{0}\right)=0$ for all $i \neq 0$. Now, using these normalizations, we can divide (4) for country 0 evaluated at state $s$ by this same equation for country 0 evaluated at state $s_{0}$ to obtain 


$$
Q(s)=\frac{1}{P_{T}(s)} \frac{\mu(s) U_{T}^{0}(s)}{\mu\left(s_{0}\right) U_{T}^{0}\left(s_{0}\right)},
$$

where $P_{T}(s)$ is given by (19). Now, for $i \neq 0$, dividing (4) for states $s$ and $s_{0}$ and then using our normalizations and the expression for $Q(s)$ in (22) implies that portfolio taxes are given by

$$
1-\tau_{D}^{i}(s)=\frac{U_{T}^{i}\left(s_{0}\right)}{U_{T}^{i}(s)} \frac{U_{T}^{0}(s)}{U_{T}^{0}\left(s_{0}\right)} .
$$

Given $P_{N}^{i}, W^{i}(s)$, and $Q^{i}(s)$, the payroll tax $\tau_{L}^{i}$ is set so that (12) holds. Domestic transfers are determined by the government budget constraint, and international transfers are given by

$$
T_{I}^{i}(s)=C_{T}^{i}(s)-Y_{T}^{i}(s) .
$$

To see that such transfers are consistent with the consumer and government budget constraints, combine these budget constraints and substitute for profits from (10) with $D^{i}(s)=0$ to obtain (24). To see that such transfers are consistent with the unionwide constraint on international transfers, integrate (24) over countries and use world market clearing in traded goods, (16), to obtain (14).

We summarize our normalizations here: we set $P_{T}\left(s_{0}\right)=1, \tau_{N}^{0}(s)=0$ for all $s$, $\tau_{N}^{i}\left(s_{0}\right)=0$ for all $i, Q^{i}\left(s_{0}\right)=1, Q^{i}(s)=Q(s)$ for all $i$ and $s, \tau_{D}^{0}(s)=0$ for all $s$, and $\tau_{D}^{i}\left(s_{0}\right)=0$ for all $i$.

Note that the competitive equilibrium is defined for each possible setting of unionwide and national policies, $\left(T_{I}, \pi\right)$. As will become clear below, in what follows it is best to think of the competitive equilibrium as the continuation equilibrium of the noncooperative equilibrium of the second stage among national governments for given union-wide policies. That is, we can think of the competitive equilibrium as specifying allocation functions, $X\left(T_{I}, \pi\right)$, a world price function, $P_{T}\left(T_{I}, \pi\right)$, and domestic price functions, $P\left(T_{I}, \pi\right)$ and $Q\left(T_{I}, \pi\right)$, that vary with union-wide and national policies, $\left(T_{I}, \pi\right)$. Noncooperative national governments will use these maps to forecast how outcomes change as they vary their national policies.

\subsection{Middle tier: noncooperative equilibrium between national authorities}

Consider now the middle tier. Taking as given the decisions of the union-wide fiscal authority, national governments set their policies noncooperatively. The policy for country $i$ 's government, $\pi^{i}=\left\{\pi^{i}(s)\right\}$, with $\pi^{i}(s)=\left(\tau_{L}^{i}, \tau_{N}^{i}(s), \tau_{D}^{i}(s), T^{i}(s)\right)$, consists of taxes on labor, the consumption of nontraded goods, and asset holdings, and of transfers. The strategy of country $i$ 's government, $\pi^{i}\left(T_{I}\right)$, depends on the history it faces, which, in this three-tiered decision-making structure, simply consists of the union-wide transfers, $T_{I}$, chosen at the top tier.

For any given set of union-wide policies, $T_{I}=\left\{T_{I}^{i}\right\}$, a noncooperative equilibrium of the incomplete market economy consists of strategies $\pi\left(T_{I}\right)=\left\{\pi^{i}\left(T_{I}\right)\right\}$ for national governments, together with the world price function, $P_{T}\left(T_{I}, \pi\right)$, and allocation and domestic price functions for each country, $\left\{X^{i}\left(T_{I}, \pi\right), P^{i}\left(T_{I}, \pi\right), Q^{i}\left(T_{I}, \pi\right)\right\}$, where 
$\pi=\left\{\pi^{i}\right\}$, such that: (i) given the union-wide policies, $T_{I}$, and the national policies of every other country $j \neq i$, denoted $\pi_{-i}\left(T_{I}\right)$, the national policy of any country $i, \pi^{i}=\pi^{i}\left(T_{I}\right)$, maximizes the welfare of country $i$ 's consumers, and (ii) for every $\left(T_{I}, \pi\right)$, the world price function, the allocation functions, and the domestic price functions form a competitive equilibrium with incomplete markets.

The noncooperative equilibrium outcomes associated with these strategies are $\pi\left(\hat{T}_{I}\right), P_{T}\left(\hat{T}_{I}, \pi\left(\hat{T}_{I}\right)\right)$, and $\left\{X^{i}\left(\hat{T}_{I}, \pi\left(\hat{T}_{I}\right)\right), P^{i}\left(\hat{T}_{I}, \pi\left(\hat{T}_{I}\right)\right), Q^{i}\left(\hat{T}_{I}, \pi\left(\hat{T}_{I}\right)\right)\right\}$, where $\hat{T}_{I}$ is the optimal policy of the union-wide authority. The noncooperative equilibrium should be thought of as simply the continuation of the world equilibrium for a given set of union-wide policies.

Consider the notion of perfection built into this noncooperative equilibrium definition. As the government of country $i$ contemplates alternative policies, $\tilde{\pi}^{i}$, it anticipates that the resulting prices and allocations, $P_{T}\left(T_{I}, \tilde{\pi}\right)$ and $\left\{X^{i}\left(T_{I}, \tilde{\pi}\right), P^{i}\left(T_{I}, \tilde{\pi}\right), Q^{i}\left(T_{I}\right.\right.$, $\tilde{\pi})$, with $\tilde{\pi}=\left(\tilde{\pi}^{i}, \pi_{-i}\left(T_{I}\right)\right)$, form a competitive equilibrium. Specifically, given the structure of the world economy, as the government of country $i$ changes its policies, consumers and firms in country $i$ change their production and consumption decisions, domestic prices change but, because country $i$ is small in the world economy, all other countries' national policies, allocations, and domestic prices are unchanged. That is, since the world price of traded goods, $P_{T}\left(T_{I}, \tilde{\pi}\right)$, with $\tilde{\pi}=\left(\tilde{\pi}^{i}, \pi_{-i}\left(T_{I}\right)\right)$, is invariant to $\tilde{\pi}^{i}$, given the union-wide transfers $T_{I}$, the government of country $i$ just faces a given world price function, say, $P_{T}=P_{T}\left(T_{I}, \pi_{-i}\left(T_{I}\right)\right)$.

We now show how this feature of equilibrium simplifies the problem of country $i$ 's government. Using logic standard in the primal approach to optimal policy, we can think of national governments as choosing policies, allocations, and domestic prices for country $i$ 's consumers and firms, subject to the conditions of the competitive equilibrium of the third stage. Formally, the problem of the government of country $i$ can be written as follows: taking as given international transfers, $T_{I}^{i}$, and traded goods prices, $P_{T}=P_{T}\left(T_{I}, \pi_{-i}\left(T_{I}\right)\right)$, choose country $i$ 's allocations, prices, and policies to solve

$$
V^{i}\left(T_{I}^{i}\right)=\max _{\left\{X^{i}(s), P^{i}(s), Q^{i}(s), \pi^{i}(s)\right\}} \sum_{s} \mu(s) U^{i}\left(C_{N}^{i}(s), C_{T}^{i}(s), L^{i}(s), s\right),
$$

subject to consumer and firm first-order conditions in country $i$, the consumer and government budget constraints in country $i$, and country $i$ 's market-clearing conditions in nontraded (15) and traded goods (17), where $P_{T}=P_{T}\left(T_{I}, \pi_{-i}\left(T_{I}\right)\right)$ in the consumer and government budget constraints. ${ }^{1}$ We claim that the best-response problem of a noncooperative government can be reduced to a simpler form, that is,

$$
V^{i}\left(T_{I}^{i}\right)=\max _{\left\{C_{N}^{i}(s), C_{T}^{i}(s), L^{i}(s)\right\}} \sum_{s} \mu(s) U^{i}\left(C_{N}^{i}(s), C_{T}^{i}(s), L^{i}(s), s\right),
$$

\footnotetext{
1 Here, and throughout the paper, we follow the primal approach in assuming that if there are multiple equilibria associated with its policies, a government can select the best one.
} 
subject to nontraded goods market clearing,

$$
C_{N}^{i}(s) \leq A^{i}(s) L^{i}(s) \text { for all } s
$$

and a country-wide budget constraint,

$$
C_{T}^{i}(s) \leq Y_{T}^{i}(s)+T_{I}^{i}(s) \text { for all } s
$$

Note that since there are no international financial markets, the government of country $i$ realizes that there is no choice in the consumption of traded goods: consumers in country $i$ simply consume their endowment plus international transfers of traded goods.

Lemma 2 In an economy with incomplete markets, for any international transfers, $T_{I}$, and strategies of other governments, $\pi_{-i}\left(T_{I}\right)$, the best response of the government of country i gives rise to allocations that solve (26).

Proof: The constraints facing the government of country $i$ are summarized by the consumer budget constraint, (3), the first-order conditions for consumers, (4), (5), and (6), the market-clearing condition for domestic assets, (7), the first-order condition for nontraded goods firms, (12), the government budget constraint, (13), and the nontraded and traded goods market-clearing conditions, (15) and (17).

We first show that an allocation that is feasible for the government must satisfy (27) and (28) for country $i$. First, (15) is the same as (27), since (27) holds as an equality. Second, to see how the constraint (28) arises, substitute in the consumer budget constraint the expression for profits, $\Pi^{i}(s)=P_{N}^{i} C_{N}^{i}(s)-\left(1+\tau_{L}^{i}\right) W^{i}(s) L^{i}(s)$, the expression for domestic transfers, $T^{i}(s)$, using the government budget constraint, (13), and $D^{i}(s)=0$ from (7). After canceling terms, we obtain $P_{T}(s) C_{T}^{i}(s) \leq$ $P_{T}(s)\left[Y_{T}^{i}(s)+T_{I}^{i}(s)\right]$, which is equivalent to (28). Now, given any allocations that satisfy (27) and (28), we can construct national policies and national prices as we did in Lemma 1 so that the rest of the constraints are satisfied.

To develop some intuition for why a noncooperative government's problem can be reduced to a country-specific Ramsey-type problem, note that each country $i$ is small and, hence, the domestic allocations, prices, and policies chosen by the government of this country cannot have an impact on world prices. Moreover, the policy choices of the countries in the rest of the union only affect a given country indirectly through traded goods prices, which are set competitively.

Lemma 2 makes it clear that, given the vector of international transfers for each country, $\left\{T_{I}^{i}\right\}$, world prices, $P_{T}$, and the maximizing behavior of the government of country $i$, the resulting utility of country $i$ only depends on the international transfers to country $i$. Thus, Lemma 2 establishes the precise sense in which no fiscal externalities across countries exist. 


\subsection{Top tier: world equilibrium}

The union-wide authority chooses international transfers to maximize a weighted sum of consumers' utility in each country, that is, to solve

$$
\max _{\left\{T_{I}^{i}\right\}} \int_{i} \lambda^{i} V^{i}\left(T_{I}^{i}\right) \mathrm{d} i
$$

subject to

$$
\int_{i} T_{I}^{i}(s) \mathrm{d} i=0 \quad \text { for all } s .
$$

Notice that the union-wide authority predicts that as it changes its transfers, the noncooperative governments will alter their policies, and thus the associated prices and allocations, so that the solution to (26) arises as a noncooperative equilibrium. In particular, for every set of transfers $\tilde{T}_{I}$ it contemplates, the union-wide authority predicts that the national governments will choose policies $\pi\left(\tilde{T}_{I}\right)$ consistent with a noncooperative equilibrium.

A world equilibrium with incomplete markets is a set of union-wide transfers, $T_{I}$, strategies for national governments, together with the world price function, and allocation and domestic price functions for each country, such that: (i) the unionwide transfers, $T_{I}$, are optimal for the union-wide authority, and (ii) the strategies for national governments, together with the world price function, allocation functions, and domestic price functions for each country, form a noncooperative equilibrium.

This notion also has a type of perfection built into it: as the union-wide authority contemplates alternative transfers, $\tilde{T}_{I}$, it understands that national governments will best respond to each such set of transfers using $\pi\left(\tilde{T}_{I}\right)$ and the resulting competitive equilibrium allocations and prices will be those consistent with $\tilde{T}_{I}$ and $\pi\left(\tilde{T}_{I}\right)$.

Using standard primal logic, we can think of the union-wide authority as choosing all policies, allocations, and prices subject to two sets of conditions. ${ }^{2}$ The first set are all the first-order conditions of consumers and firms, the budget constraints of consumers and governments, and the market-clearing conditions that define the competitive equilibrium. The second set are the optimality conditions for the policies of each government's best-response problem. Notice that since the consumption of traded goods is pinned down by the endowment of traded goods and international transfers, the only optimality conditions from the government's best-response problem are for nontraded goods and labor. Substituting the constraints (27) and (28), holding as equalities, into the objective function (26), these first-order conditions for nontraded goods and labor reduce to

$$
A^{i}(s) U_{N}^{i}(s)+U_{L}^{i}(s)=0 .
$$

\footnotetext{
${ }^{2}$ Here, as is standard in the primal approach, if there are multiple continuation equilibria for a given set of policies, we implicitly let both the union-wide authority and the national governments select the best such equilibrium.
} 
If allocations satisfy (28) and the union-wide authority chooses international transfers that satisfy (30), then the union-wide authority is only constrained by the nontraded and world traded goods market-clearing conditions, along with the first-order conditions in (31). Now consider a relaxed version of the authority's problem, where we substitute out all the policies and drop the first-order condition (31), which arises from (26). This relaxed problem, referred to as the union-wide problem, is

$$
\max _{\left\{C_{N}^{i}(s), C_{T}^{i}(s), L^{i}(s)\right\}} \int_{i} \lambda^{i}\left[\sum_{s} \mu(s) U^{i}\left(C_{N}^{i}(s), C_{T}^{i}(s), L^{i}(s), s\right)\right] \mathrm{d} i
$$

subject to

$$
\begin{aligned}
& C_{N}^{i}(s) \leq A^{i}(s) L^{i}(s) \text { for all } s, \\
& \int_{i} C_{T}^{i}(s) \mathrm{d} i \leq \int_{i} Y_{T}^{i}(s) \mathrm{d} i \text { for all } s .
\end{aligned}
$$

We claim that it is immediate that the solution to this relaxed problem has firstorder conditions that are consistent with the dropped first-order condition (31) of the government's best-response problem. Moreover, policies and prices can be constructed so that a solution to this relaxed problem satisfies the rest of the dropped constraints of the original problem. Hence, the solution to the relaxed problem coincides with the solution to the original problem. We summarize this discussion as follows.

Lemma 3 The allocations in the world equilibrium with incomplete markets solve the union-wide problem (32).

\section{A currency-fiscal union with complete financial markets}

Here we consider a joint currency-fiscal union with complete international financial markets. We think of this complete market setting as capturing the idea that in the modern era of international financial markets, countries can access these markets to obtain cross-country insurance. We again work backwards from the end of the period, starting from the competitive equilibrium.

\subsection{Bottom tier: competitive equilibrium}

We begin with a definition of a competitive equilibrium. Given the policies of the union-wide authority, $\left\{T_{I}^{i}\right\}$, and the national policies, $\left\{\pi^{i}\right\}$, a competitive equilibrium with complete markets consists of world prices, $P_{T}$ and $Q$, together with allocations, $\left\{X^{i}\right\}$, and domestic prices, $\left\{P^{i}\right\}$, for each country $i$ such that: (i) consumer maximization in each country $i$ holds, (ii) profit maximization for both final goods firms and intermediate goods firms in each country $i$ holds, (iii) the national policy, $\pi^{i}$, satisfies the government budget constraint of each country $i$, (13), (iv) the union-wide policies, $\left\{T_{I}^{i}\right\}$, satisfy the budget constraint of the union-wide authority, (14), (v) the world asset market clears in that 


$$
\int_{i} D^{i}(s) \mathrm{d} i=0 \text { for all } s,
$$

and (vi) the nontraded and world traded goods markets clear in that

$$
\begin{aligned}
& C_{N}^{i}(s)=A^{i}(s) L^{i}(s) \text { for all } i \text { and } s, \\
& \int_{i} C_{T}^{i}(s) \mathrm{d} i=\int_{i} Y_{T}^{i}(s) \mathrm{d} i \text { for all } s .
\end{aligned}
$$

Note that with complete markets, there is now one world asset market rather than separate domestic asset markets. Given complete markets, any vector of international transfers to country $i$, namely, $T_{I}^{i}=\left\{T_{I}^{i}(s)\right\}$, with the same present value is equivalent from the perspective of both the consumers and the government of country $i$. Thus, in defining a world equilibrium, there will be an indeterminacy in international transfers because any two sets of transfers, $\left\{T_{I}^{i}(s)\right\}$ and $\left\{\tilde{T}_{I}^{i}(s)\right\}$, are equivalent if they satisfy

$$
\sum_{s} Q(s) P_{T}(s) T_{I}^{i}(s)=\sum_{s} Q(s) P_{T}(s) \tilde{T}_{I}^{i}(s),
$$

for given $Q(s)$ and $P_{T}(s)$. We resolve this indeterminacy by representing international transfers as a constant transfer across states, $T_{I}^{i, c}$, such that $T_{I}^{i}(s)=T_{I}^{i, c}$ for all $s$. Here, as earlier, we can think of equilibrium as specifying allocation functions, $X\left(T_{I}^{c}, \pi\right)$, world price functions, $P_{T}\left(T_{I}^{c}, \pi\right)$ and $Q\left(T_{I}^{c}, \pi\right)$, and domestic price functions, $P\left(T_{I}^{c}, \pi\right)$, that vary with union-wide and national policies, $\left(T_{I}^{c}, \pi\right)$. The proof of the following lemma is nearly identical to that of Lemma 1 and is left to the reader.

Lemma 4 The allocations in a competitive equilibrium with complete markets satisfy the nontraded and world traded goods market-clearing conditions, namely, (36) and (37). Moreover, given any allocations that satisfy these constraints, we can construct prices, policies, and asset holdings for each country that, together with the given allocations, constitute a competitive equilibrium with complete markets.

\subsection{Middle tier: noncooperative equilibrium between national authorities}

Consider now the middle tier. As before, taking as given the decisions of the unionwide authority, national governments set their policies noncooperatively. For any given set of union-wide policies, $T_{I}^{c}=\left\{T_{I}^{i, c}\right\}$, a noncooperative equilibrium of the complete market economy consists of strategies $\pi\left(T_{I}^{c}\right)=\left\{\pi^{i}\left(T_{I}^{c}\right)\right\}$ for national governments, together with world price functions, $P_{T}\left(T_{I}^{c}, \pi\right)$ and $Q\left(T_{I}^{c}, \pi\right)$, and allocation and domestic price functions for each country, $\left\{X^{i}\left(T_{I}^{c}, \pi\right), P^{i}\left(T_{I}^{c}, \pi\right)\right\}$, where $\pi=\left\{\pi^{i}\right\}$, such that: (i) given the union-wide policies, $T_{I}^{c}$, and the national policies of every other country $j \neq i$, denoted $\pi_{-i}\left(T_{I}^{c}\right)$, the national policy of any country $i, \pi^{i}=\pi^{i}\left(T_{I}^{c}\right)$, maximizes the welfare of country $i$ 's consumers, and (ii) for every $\left(T_{I}^{c}, \pi\right)$, the world price functions, the allocation functions, and the domestic price functions form a competitive equilibrium with complete markets. 
Using logic similar to that used before, the best response of a noncooperative government can be reduced to a simpler form, that is,

$$
V^{i}\left(T_{I}^{i, c}\right)=\max _{\left\{C_{N}^{i}(s), C_{T}^{i}(s), L^{i}(s)\right\}} \sum_{s} \mu(s) U^{i}\left(C_{N}^{i}(s), C_{T}^{i}(s), L^{i}(s), s\right),
$$

subject to nontraded goods market clearing,

$$
C_{N}^{i}(s) \leq A^{i}(s) L^{i}(s) \text { for all } s,
$$

and a country-wide budget constraint,

$$
\sum_{s} Q(s) P_{T}(s) C_{T}^{i}(s) \leq \sum_{s} Q(s) P_{T}(s)\left[Y_{T}^{i}(s)+T_{I}^{i, c}\right]
$$

where $P_{T}=P_{T}\left(T_{I}^{c}, \pi_{-i}\left(T_{I}^{c}\right)\right)$ and $Q=Q\left(T_{I}^{c}, \pi_{-i}\left(T_{I}^{c}\right)\right)$. Here, as earlier, we use the property that world prices do not vary with the policies of country $i$.

Lemma 5 In an economy with complete markets, for any international transfers, $T_{I}^{c}$, and strategies of other governments, $\pi_{-i}\left(T_{I}^{c}\right)$, the best response of the government of country $i$ gives rise to allocations that solve (38).

Proof: The proof follows closely that of Lemma 2 with a few exceptions. The constraints facing the government of country $i$ are the same as in Lemma 2 except that the asset market-clearing condition (7) is replaced by (35). To see that a feasible allocation for the government must satisfy the country-wide budget constraint (40), substitute in the consumer budget constraint the expression for profits, $\Pi^{i}(s)=P_{N}^{i} C_{N}^{i}(s)-\left(1+\tau_{L}^{i}\right) W^{i}(s) L^{i}(s)$, the expression for domestic transfers, $T^{i}(s)$, from the government budget constraint, (13), and cancel terms, to obtain $P_{T}(s) C_{T}^{i}(s) \leq P_{T}(s)\left[Y_{T}^{i}(s)+T_{I}^{i, c}\right]+D^{i}(s)$. Then, multiply this constraint for each $s$ by the world asset price $Q(s)$, sum across states, and use the asset market constraint (2) to arrive at (40).

Now, given any allocations that satisfy (39) and (40), we can construct national policies and national prices so that the rest of the constraints are satisfied. Here country $i$ takes as given the world prices, $Q(s)$ and $P_{T}(s)$. Given these prices, we proceed as in Lemma 1 , by using the normalizations $\tau_{D}^{i}\left(s_{0}\right)=0, Q\left(s_{0}\right)=1$, and $P_{T}\left(s_{0}\right)=1$ so that (4) implies

$$
1-\tau_{D}^{i}(s)=\frac{\mu\left(s_{0}\right)}{\mu(s)} \frac{U_{T}^{i}\left(s_{0}\right)}{U_{T}^{i}(s)} Q(s) P_{T}(s)
$$

and let (41) determine $\tau_{D}^{i}(s)$. (In contrast to Lemma 1, where we also constructed world prices, here we only characterize the best response of a government given these prices.) The rest of the argument follows analogously to those in Lemmas 1 and 2. 


\subsection{Top tier: world equilibrium}

A world equilibrium with complete markets is a set of union-wide transfers, $T_{I}^{c}$, strategies for national governments, together with world price functions, and allocation and domestic price functions for each country, such that: (i) the union-wide transfers, $T_{I}^{c}$, are optimal for the union-wide authority, and (ii) the strategies for national governments, together with the world price functions, allocation functions, and domestic price functions for each country, form a noncooperative equilibrium.

As before, using standard primal logic, the union-wide authority can be thought of as choosing all the policies, allocations, and prices subject to two sets of conditions. The first set are all the first-order conditions of consumers and firms, the budget constraints of consumers and governments, and the market-clearing conditions that define the competitive equilibrium of the third stage. The second set are the optimality conditions for the policies of each government's best-response problem. Now consider a relaxed version of this authority's problem, where we substituted out all the policies and dropped the first-order conditions of national governments that arise from the rewritten government's problem (38). This relaxed problem has the form

$$
\max _{\left\{C_{N}^{i}(s), C_{T}^{i}(s), L^{i}(s)\right\}} \int_{i} \lambda^{i}\left[\sum_{s} \mu(s) U^{i}\left(C_{N}^{i}(s), C_{T}^{i}(s), L^{i}(s), s\right)\right] \mathrm{d} i
$$

subject to

$$
C_{N}^{i}(s) \leq A^{i}(s) L^{i}(s) \text { and } \int_{i} C_{T}^{i}(s) \mathrm{d} i \leq \int_{i} Y_{T}^{i}(s) \mathrm{d} i \text { for all } s .
$$

Clearly, we can construct prices $Q(s)$ and $P_{T}(s)$ and international transfers so that the solution to this relaxed problem has first-order conditions that are consistent with the first-order conditions of each government's best-response problem in (38). Moreover, these prices and policies can be constructed so that a solution to the relaxed problem satisfies the rest of the dropped constraints of the original problem. Thus, the solution to the relaxed problem is a solution to the original problem. In sum, we have established the following result.

Lemma 6 The allocations in the world equilibrium with complete markets solve the union-wide problem (42).

Note that the union-wide problem with complete markets coincides with that with incomplete markets. The intuition is that with incomplete markets, appropriately chosen union-wide transfers exactly mimic the risk-sharing payments made under complete markets. Moreover, in the world equilibrium with complete markets that decentralizes the corresponding allocations, portfolio taxes are not used. To see why, note that the solution to the union-wide problem implies complete risk sharing in that

$$
\lambda^{i} U_{T}^{i}(s)=\lambda^{0} U_{T}^{0}(s) \text { for all } i \text { and } s .
$$


Dividing this condition by its analog in state $s_{0}$ gives that allocations with complete risk sharing satisfy

$$
\frac{U_{T}^{i}(s)}{U_{T}^{i}\left(s_{0}\right)}=\frac{U_{T}^{0}(s)}{U_{T}^{0}\left(s_{0}\right)} \text { for all } i \text { and } s .
$$

Now, consider the decentralized equilibrium. With complete international financial markets, which imply $Q^{i}(s)=Q(s)$ for all $i$, the first-order condition (4) implies that

$$
\frac{\left[1-\tau_{D}^{i}(s)\right] \mu(s) U_{T}^{i}(s)}{\left[1-\tau_{D}^{i}\left(s_{0}\right)\right] \mu\left(s_{0}\right) U_{T}^{i}\left(s_{0}\right)}=\frac{\left[1-\tau_{D}^{0}(s)\right] \mu(s) U_{T}^{0}(s)}{\left[1-\tau_{D}^{0}\left(s_{0}\right)\right] \mu\left(s_{0}\right) U_{T}^{0}\left(s_{0}\right)}=Q(s) P_{T}(s),
$$

where we have used the normalizations that $Q\left(s_{0}\right)=P_{T}\left(s_{0}\right)=1$. Clearly, the allocations that satisfy (44) can be supported as competitive allocations with $\tau_{D}^{i}(s)=0$ for all $i$ and $s$. In this sense, portfolio taxes are redundant given nontraded goods taxes.

More generally, if we dropped the portfolio tax from the list of instruments a government controls, then we would obtain the same results as we did earlier, including Lemmas 3 and 6. To see why, consider first the economy with complete markets and note that if we endow governments only with a payroll tax and a nontraded goods tax, then the allocations that solve the best-response problem for noncooperative governments would also solve (38). To understand this result, note that with $\tau_{D}^{i}(s)=0$ for all $i$ and $s$, dividing the first-order condition (4) in a given country $i$ for state $s$ by the corresponding one for state $s_{0}$ gives that allocations must satisfy the extra constraint

$$
\frac{\mu(s) U_{T}^{i}(s)}{\mu\left(s_{0}\right) U_{T}^{i}\left(s_{0}\right)}=Q(s) P_{T}(s) \text { for all } s \neq s_{0} .
$$

This constraint would then need to be added to the best-response problem (38). To see that this extra constraint is superfluous, consider a relaxed version of this problem without the constraint in (46). The first-order conditions to the relaxed problem then imply (46), so the solution to the relaxed problem is feasible for the original problem with this constraint and hence solves it. It is thus immediate that the union-wide problem is unchanged. A similar argument holds with incomplete markets. Portfolio taxes are not used in Lemma 2, so Lemma 3 would also hold without portfolio taxes. Then, the union-wide problem with incomplete markets would be unchanged if we dropped portfolio taxes.

\section{Do financial markets obviate the need for a fiscal union?}

We have argued that the key difference between Mundell's and Kenen's views of a union is that Mundell envisions a union in which international transfers are motivated solely by insurance reasons, whereas Kenen imagines a union in which these transfers are motivated by redistributive reasons as well. To formalize these different views, we need to distinguish clearly a union's goal of providing insurance to member countries from its goal of redistributing ex-ante wealth. 
Given our setup with self-interested consumers and governments acting on behalf of their own citizens, obviously no government will willingly give away ex-ante wealth. Hence, regardless of how sophisticated international financial markets are, if the goal of a union is to redistribute ex-ante wealth, a union-wide authority is needed to extract ex-ante resources from one group of countries and redistribute them to another. That is, under Kenen's view, an activist union-wide authority is necessary to implement such a redistribution.

We claim that the key difference between Mundell's and Kenen's views of a union amounts to different specifications of the Pareto weights used by the union-wide authority when deciding on international transfers. Specifically, for an arbitrary set of welfare weights, $\lambda=\left\{\lambda^{i}\right\}$, a union-wide authority both provides insurance and redistributes ex-ante wealth. To focus on insurance only, we proceed as follows. For any given set of weights, we construct our decentralization of the allocations from the union-wide problem in the incomplete market equilibrium, (32), as in Lemma 1, with artificial prices $Q(s ; \lambda)$ and $P_{T}(s ; \lambda)$ and associated consumption levels $\left\{C_{T}^{i}(s ; \lambda)\right\}$. The international transfers that decentralize this problem are defined by

$$
T_{I}^{i}(s ; \lambda)=Y_{T}^{i}(s)-C_{T}^{i}(s ; \lambda)
$$

that is, $T_{I}^{i}(s ; \lambda)$ are the transfers in state $s$ given to each consumer in country $i$ when the union-wide authority uses the Pareto weights $\lambda$. Under the decentralization of this problem, these transfers have an ex-ante value of

$$
W_{I}^{i}(\lambda)=\sum_{s} Q(s ; \lambda) P_{T}(s ; \lambda) T_{I}^{i}(s ; \lambda) .
$$

We say that the weights $\lambda$ involve no ex-ante transfer of wealth between countries if

$$
W_{I}^{i}(\lambda)=0 \quad \text { for all } i \in I .
$$

We say that a union-wide fiscal authority is concerned solely with insurance if its objective function has Pareto weights that involve no ex-ante transfer of wealth between countries, and has redistributive motives otherwise.

In short, according to Mundell's view, in the incomplete markets era, the unionwide authority has weights that satisfy (49). Given these weights, we then address Mundell's question: In the modern era of complete markets, is there any role for an activist union-wide policy of transfers? More precisely, we say that the union-wide fiscal authority is unnecessary with complete markets if the allocations in the world equilibrium in which this authority implements international transfers coincide with those in the world equilibrium in which all international transfers are restricted to zero. That is, letting $T_{I}^{i, c}(\lambda)$ denote the equilibrium transfers under complete markets, the union-wide authority is unnecessary if $T_{I}^{i, c}(\lambda)=0$ for all $i$. The following is our first main proposition.

Proposition 1 (Complete Markets Obviate the Need for a Fiscal Union) A union-wide fiscal authority is unnecessary with complete markets if and only if this authority is concerned solely with insurance. 
Proof: Recall that the problem of the union-wide authority with incomplete markets reduces to the same problem as it does with complete markets. Accordingly, we start with the allocations that a union-wide authority would choose to implement with a system of international transfers when markets are incomplete. We then show that these same allocations would arise in an equilibrium with complete markets with no intervention by the union-wide authority, as long as the union-wide authority is concerned solely with insurance.

The problem of the union-wide authority with incomplete markets reduces to the one in (32). Let $\left\{C_{T}^{i}(s ; \lambda)\right\}$ and $Q(s ; \lambda)$ denote the traded goods allocations and the artificial prices for this problem. The first-order conditions imply perfect risk sharing in that

$$
\lambda^{i} U_{T}^{i}(s ; \lambda)=\lambda^{0} U_{T}^{0}(s ; \lambda) \text { for all } i \text { and } s,
$$

which yield

$$
\frac{U_{T}^{i}(s ; \lambda)}{U_{T}^{i}\left(s_{0} ; \lambda\right)}=\frac{U_{T}^{0}(s ; \lambda)}{U_{T}^{0}\left(s_{0} ; \lambda\right)} \quad \text { for all } i \text { and } s .
$$

Using the decentralization in Lemma 1, we obtain

$$
P_{T}(s ; \lambda)=\frac{U_{T}^{0}(s ; \lambda) / U_{N}^{0}(s ; \lambda)}{U_{T}^{0}\left(s_{0} ; \lambda\right) / U_{N}^{0}\left(s_{0} ; \lambda\right)} \quad \text { and } \quad Q(s ; \lambda)=\frac{1}{P_{T}(s ; \lambda)} \frac{\mu(s) U_{T}^{i}(s ; \lambda)}{\mu\left(s_{0}\right) U_{T}^{i}\left(s_{0} ; \lambda\right)},
$$

where (51) and (52) imply that $Q(s ; \lambda)$ does not vary with the country $i$. The transfers are

$$
T_{I}^{i}(s ; \lambda)=Y_{T}^{i}(s)-C_{T}^{i}(s ; \lambda),
$$

that is, $T_{I}^{i}(s ; \lambda)$ are the transfers in state $s$ given to each consumer in country $i$ when the union-wide authority uses the Pareto weights $\lambda$. These transfers involve no ex-ante transfer of wealth between countries if

$$
W_{I}^{i}(\lambda)=\sum_{s} Q(s ; \lambda) P_{T}(s ; \lambda) T_{I}^{i}(s ; \lambda)=0 \text { for all } i
$$

Now consider the problem of the union-wide authority with complete markets. As we have argued, that problem reduces to (42) and thus its solution implies the same allocations $\left\{C_{T}^{i}(s ; \lambda)\right\}$ as those implied by the problem in (32). We can decentralize these allocations as we did in Lemma 4. Clearly, the prices that decentralize these allocations as a complete market equilibrium equal the prices that decentralize them as an incomplete market equilibrium. The state-uncontingent transfers $T_{I}^{i, c}(\lambda)$ under the complete market decentralization are related to the state-contingent transfers $T_{I}^{i}(s ; \lambda)$ under the incomplete market decentralization by

$$
T_{I}^{i, c}(\lambda) \sum_{s} Q(s ; \lambda) P_{T}(s ; \lambda)=\sum_{s} Q(s ; \lambda) P_{T}(s ; \lambda) T_{I}^{i}(s ; \lambda) .
$$

Thus, for the weights $\lambda$ that involve no ex-ante transfer of wealth under incomplete markets, namely, those that satisfy (49), the complete market transfers necessarily satisfy 


$$
T_{I}^{i, c}(\lambda)=0 \text { for all } i .
$$

Hence, (56) establishes that a union-wide fiscal authority is unnecessary with complete markets if and only if this authority is concerned solely with insurance.

\section{Do restrictions on policies generate fiscal externalities?}

So far we have considered economies in which national governments have available rich enough fiscal instruments that the distortions associated with monopoly power, sticky prices, and a fixed exchange rate can be eliminated by a suitable choice of policies. Thus, with such instruments and complete markets, each national government can maximize its citizens' welfare subject only to a country-wide budget constraint and the nontraded goods resource constraint.

Here we consider economies in which national governments have a restricted set of fiscal instruments available so that they cannot eliminate all private distortions. The question we address is the following: Does restricting the set of fiscal instruments of national governments introduce a fiscal externality across countries? That is, with restricted policy instruments, is a union-wide fiscal authority necessary to achieve the relevant constrained-efficient outcomes? Our answer is no: even with restricted instruments, no fiscal externality arises and, thus, a union-wide fiscal authority is unnecessary if the authority is concerned solely with insurance.

\subsection{Restrictions on policies}

Here we restrict governments to have no domestic policy instrument that affects the relative prices of traded and nontraded goods, that is, we make the restricted policy assumption that

$$
\tau_{N}^{i}(s)=0 \text { for all } i \text { and } s .
$$

We again proceed by working backwards from the end of the period. To characterize the set of allocations that can be implemented by a suitable choice of policy, consider the first-order conditions of consumers in (4)-(6) and the intermediate goods firms in (12) under the restricted policy assumption. We claim that in addition to the resource constraints, these allocations must satisfy some additional constraints that we refer to as incomplete tax constraints. To see how these constraints arise, note that with $\tau_{N}^{i}(s)$ restricted to zero and the normalization that $P_{T}\left(s_{0}\right)=1$, the first-order condition (5) implies

$$
\frac{U_{T}^{i}(s) / U_{N}^{i}(s)}{U_{T}^{i}\left(s_{0}\right) / U_{N}^{i}\left(s_{0}\right)}=P_{T}(s),
$$

where the right side does not vary across countries. ${ }^{3}$ Thus, the left side of (58) must be the same across all countries $i$ for any given state $s$. Letting $R^{i}(s) \equiv U_{T}^{i}(s) / U_{N}^{i}(s)$,

\footnotetext{
${ }^{3}$ Of course, if exchange rates were flexible so that each country had its own nominal price of traded goods, $P_{T}^{i}(s)$, then even with $\tau_{N}^{i}(s)$ restricted to zero, the right side of this first-order condition would vary with $i$ and there would be no such restriction.
} 
we can compactly express these constraints relative to some particular country, say, $i=0$, as

$$
\frac{R^{i}(s)}{R^{i}\left(s_{0}\right)}=\frac{R^{0}(s)}{R^{0}\left(s_{0}\right)} \text { for all } i \text { and } s .
$$

Hence, for each country $i \neq 0$, there is one constraint per state $s \neq s_{0}$. Here we discuss how these incomplete tax constraints change the analysis in the incomplete and complete market economies.

\subsection{Incomplete markets with restricted policies}

We again proceed with each tier. A competitive equilibrium with incomplete markets and restricted policies is defined analogously to that of our economy with unrestricted instruments. The lemma characterizing the competitive equilibrium is the analog of Lemma 1.

Lemma 7 The allocations in a competitive equilibrium with incomplete markets and restricted policies satisfy the nontraded and world traded goods market-clearing conditions, namely, (15) and (16), and the incomplete tax constraints (59). Moreover, given any allocations that satisfy these constraints, we can construct prices and policies for each country that, together with the given allocations, constitute a competitive equilibrium with incomplete markets and restricted policies.

Proof: For necessity, by definition of an equilibrium, the allocations satisfy the nontraded and world traded goods market-clearing conditions. To see that they must also satisfy the incomplete tax constraints, divide each term in (5) for some state $s$ by its counterpart in state $s^{\prime}$, imposing $\tau_{N}^{i}(s)=\tau_{N}^{i}\left(s^{\prime}\right)=0$ to get

$$
\frac{R^{i}(s)}{R^{i}\left(s^{\prime}\right)}=\frac{P_{T}(s)}{P_{T}\left(s^{\prime}\right)} .
$$

To see that (60) implies (59), pick state $s^{\prime}$ to be state $s_{0}$ and divide (60) for country $i$ by the same constraint for country 0 . This yields (59). For sufficiency, the construction follows the same steps as in Lemma 1.

As for the middle tier, given the policies of the union-wide authority, $T_{I}=\left\{T_{I}^{i}\right\}$, a noncooperative equilibrium of the incomplete market economy is defined as before except that the domestic price functions form a competitive equilibrium with incomplete markets and restricted policies. We claim that it is immediate from Lemma 7 and the definition of the noncooperative equilibrium that the best response of country $i$ 's government implies allocations that solve

$$
V^{i}\left(T_{I}^{i}\right)=\max _{\left\{C_{T}^{i}(s), L^{i}(s)\right\}} \sum_{s} \mu(s) U^{i}\left(A^{i}(s) L^{i}(s), C_{T}^{i}(s), L^{i}(s), s\right),
$$

subject to a country-wide budget constraint,

$$
C_{T}^{i}(s) \leq Y_{T}^{i}(s)+T_{I}^{i}(s) \text { for all } s
$$


and the incomplete tax constraints,

$$
R^{i}(s)=P_{T}(s) R^{i}\left(s_{0}\right) \text { for } s \neq s_{0}
$$

which follows from (58), with $P_{T}\left(s_{0}\right)=1$ and $P_{T}=P_{T}\left(T_{I}, \pi_{-i}\left(T_{I}\right)\right)$. The reason a government's best response solves this problem is that, taking as given the union-wide policy $\left\{T_{I}^{i}\right\}$ and the strategies $\pi_{-i}\left(T_{I}\right)$ of other governments, the government of country $i$ can manipulate its national policies to implement any allocation that satisfies (62) and (63). Notice that with restricted instruments, the constraints in (63) imply that we can no longer reduce this best-response problem to one in which all the traded goods prices have been substituted out, as we did earlier with unrestricted instruments. The presence of these extra constraints, (63), clearly introduces additional distortions into this problem relative to the one with an unrestricted tax system. Here, the incomplete tax constraints typically bind when countries face different shocks. Hence, the analog of Lemma 3 is immediate.

Lemma 8 The allocations in the world equilibrium with incomplete markets and restricted policies solve the union-wide problem of maximizing the objective function in (32), subject to the resource constraints for nontraded goods, the world resource constraints for traded goods, and the incomplete tax constraints in (59).

For any given set of weights $\lambda=\left\{\lambda^{i}\right\}$, for the proof of this lemma we construct our decentralization of the solution to the union-wide problem for the incomplete market economy with restricted instruments as in Lemma 1 , with prices $\left\{Q^{i}(s ; \lambda)\right\}$ and associated consumption levels $\left\{C_{T}^{i}(s ; \lambda)\right\}$. The international transfers that decentralize this problem satisfy (47).

\subsection{Complete markets with restricted policies}

The analysis here is an immediate extension of our analysis above. The key lemma for the competitive equilibrium is the analog of Lemma 7.

Lemma 9 The allocations in a competitive equilibrium with complete markets and restricted policies satisfy the nontraded and world traded goods market-clearing conditions, namely, (15) and (16), and the incomplete tax constraints (59). Moreover, given any allocations that satisfy these constraints, we can construct prices, policies, and asset holdings for each country that, together with the given allocations, constitute a competitive equilibrium with complete markets and restricted policies.

Given the world prices $P_{T}$ and $Q$ and the (state-uncontingent) international transfers $T_{I}^{i, c}$, the problem of the noncooperative government of country $i$ is to choose allocations to maximize the welfare of country $i$, that is,

$$
\max _{\left\{C_{T}^{i}(s), L^{i}(s)\right\}} \sum_{s} \mu(s) U^{i}\left(A^{i}(s) L^{i}(s), C_{T}^{i}(s), L^{i}(s), s\right)
$$


subject to

$$
\begin{aligned}
& \sum_{s} Q(s) P_{T}(s) C_{T}^{i}(s) \leq \sum_{s} Q(s) P_{T}(s)\left[Y_{T}^{i}(s)+T_{I}^{i, c}\right], \\
& R^{i}(s)=P_{T}(s) R^{i}\left(s_{0}\right) \text { all } s \neq s_{0},
\end{aligned}
$$

where $P_{T}$ and $Q$ are defined as functions of $\left(T_{I}^{c}, \pi_{-i}\left(T_{I}^{c}\right)\right)$ and are part of a competitive equilibrium with complete markets and restricted policies. The problem of the unionwide authority is defined as before. The definitions of a union-wide authority being concerned solely with insurance, having redistributive motives, and being unnecessary with complete markets are the natural analogs of those introduced earlier for the economy with no restrictions on instruments. The second main result of the paper is summarized in the following proposition.

Proposition 2 (Complete Markets Obviate the Need for a Fiscal Union Even with Restricted Policies) In an economy with restricted policies, a union-wide fiscal authority is unnecessary with complete markets if and only if this authority is concerned solely with insurance.

Proof: The proof is essentially identical to that of Proposition 1. The union-wide authority's problems under incomplete and complete markets reduce to the same planning problem, namely, to maximize the objective function of the union subject to the resource constraints for nontraded goods (33), the world resource constraints for traded goods (34), and the incomplete tax constraints (59). Using the decentralizations of Lemmas 7, 8, and 9, if the weights that decentralize the incomplete market allocations imply international transfers $\left\{T_{I}^{i}(s ; \lambda)\right\}$ that involve no ex-ante transfer of wealth in that $\sum_{s} Q(s ; \lambda) P_{T}(s ; \lambda) T_{I}^{i}(s ; \lambda)=0$, then clearly for those same weights, the complete market transfers, $\left\{T_{I}^{i, c}(\lambda)\right\}$, that decentralize these same outcomes necessarily satisfy $T_{I}^{i, c}(\lambda) \sum_{s} Q(s ; \lambda) P_{T}(s ; \lambda)=0$ for all $i$, so that $T_{I}^{i, c}(\lambda)=0$ for all $i$.

\section{When is there a role for an activist union-wide authority?}

We have shown that for the economies considered, there is no role for an activist union-wide authority under complete markets when that authority is concerned solely with insurance. Here we determine conditions under which there might be a role for such an authority.

Our results so far depend on the premise that the union-wide authority has no access to instruments that national governments do not have available, except for international transfers, and that the national government of each country is benevolent in that it chooses policies to maximize the welfare of its citizens. It is primarily the combination of these two assumptions, along with the assumption that policy makers have commitment and that each country is small in the world in the relevant sense, which allows us to establish this result. If we drop any of these assumptions, there may be a role for a union-wide authority, even one concerned solely with insurance. 
We prove this point through three examples. Our first example shows that if some countries are constrained in their choice of policy instruments, then there is a role for an active union-wide authority to levy portfolio taxes. Our second example shows that even when countries have flexible exchange rates, if national governments face constraints on their policies, then the union-wide authority typically has an incentive to intervene and impose portfolio taxes. Finally, our last example shows that if national governments do not maximize the welfare of their citizens but rather pursue their own self-interests, then there is an incentive for the union as a whole to delegate the power to set portfolio taxes to the union-wide authority rather than to the national governments.

\subsection{Portfolio taxes to help policy-constrained countries in a union}

Suppose that all countries in one group of the union, $N$ or the North, have access to labor taxes, nontraded goods taxes, and lump-sum transfers, $\left\{\tau_{L}^{i}, \tau_{N}^{i}(s), T^{i}(s)\right\}$ for $i \in N$, but that countries in another group, $S$ or the $S$ outh, have access only to labor taxes and lump-sum transfers, $\left\{\tau_{L}^{i}, T^{i}(s)\right\}$ for $i \in S$. Suppose, moreover, that the union-wide authority, rather than national governments, can levy taxes on the portfolios of all countries in the union, $\left\{\tau_{D}^{i}(s)\right\}$ for all $i$, and when it levies such taxes on a country, it rebates the proceeds to that country.

Clearly, the restrictions on the fiscal instruments of Southern countries add incomplete tax constraints of the form

$$
\frac{R^{i}(s)}{R^{i}\left(s_{0}\right)}=\frac{R^{0}(s)}{R^{0}\left(s_{0}\right)} \text { for all } i \in S \text { and } s \neq s_{0}
$$

where country 0 is a Southern country. Now, given that the union-wide authority can levy portfolio taxes $\left\{\tau_{D}^{i}(s)\right\}$ on any country, it is easy to show that the problem of the union-wide authority reduces to

$$
\max _{\left\{C_{T}^{i}(s), L^{i}(s)\right\}} \int_{i} \lambda^{i}\left[\sum_{s} \mu(s) U^{i}\left(A^{i}(s) L^{i}(s), C_{T}^{i}(s), L^{i}(s), s\right)\right] \mathrm{d} i,
$$

subject to the incomplete tax constraints for the Southern countries in (64) and the world resource constraints for traded goods. Now consider two pairs of countries, countries $i, j \in N$ and $k, l \in S$. The first-order conditions of consumers imply that for all $s$

$$
\lambda^{i} U_{T}^{i}(s)=\lambda^{j} U_{T}^{j}(s)=\lambda^{k} U_{T}^{k}(s)+\phi^{k}(s)=\lambda^{l} U_{T}^{l}(s)+\phi^{l}(s),
$$

where for $m=k, l, m \neq 0$, and $s \neq s_{0}$,

$$
\phi^{m}(s)=-\lambda^{m}\left[A^{m}(s) U_{N}^{m}(s)+U_{L}^{m}(s)\right] \frac{\partial R^{m}(s) / \partial C_{T}^{m}(s)}{\partial R^{m}(s) / \partial L^{m}(s)} .
$$


As we show in the Appendix, the expressions for $\phi^{m}(s)$ for $m \neq 0$ and $s=s_{0}$, and those for $m=0$ are similar. The first-order condition (66) implies that there is perfect risk sharing between any two Northern countries but, because of the incomplete tax constraints, there is imperfect risk sharing either between a Northern country and a Southern country or between any two Southern countries. To achieve allocations consistent with (66), the union levies the following portfolio taxes:

$$
\tau_{D}^{i}(s)=\left\{\begin{array}{ll}
0 & \text { for } i \in N \\
-\frac{1}{\lambda^{i}} \frac{\phi^{i}(s)}{U_{T}^{i}(s)} & \text { for } i \in S
\end{array} .\right.
$$

To see why, note that in the decentralized equilibrium with complete markets, the first-order conditions for consumers imply

$$
\frac{U_{T}^{i}(s)\left[1-\tau_{D}^{i}(s)\right]}{\rho^{i}}=\frac{U_{T}^{0}(s)\left[1-\tau_{D}^{0}(s)\right]}{\rho^{0}},
$$

where $\rho^{i}$ is the multiplier on the asset market constraint (2). Here with $\tau_{D}^{i}(s)$ defined by (68) and the multiplier $\rho^{i}$ set to $1 / \lambda^{i}$, the decentralized first-order conditions (69) coincide with those in the union-wide problem, (66).

Proposition 3A (Portfolio Taxes to Help Policy-Restricted Countries) In this economy with restricted policies, a union-wide fiscal authority concerned solely with insurance makes no transfers to any country and levies portfolio taxes on policyrestricted countries solely to help these countries ameliorate their distortions.

Here the union-wide authority simply helps policy-restricted countries by levying a portfolio tax, which is less powerful than the nontraded goods tax in that it only partially fixes the limited risk sharing implied by the incomplete tax system. The union-wide authority levies such a tax only because a policy-restricted country is incapable of levying a nontraded goods tax for itself that would undo the incomplete tax constraint.

Notice that here an active role for the union-wide authority is intimately connected to the countries belonging to a monetary union. To see why, suppose that countries still belong to a fiscal union, but that exchange rates between member countries of the union are flexible. In this case, each country $i$ has its own nominal price $P_{T}^{i}(s)$ for its traded goods, where $P_{T}^{i}(s)$ is the price of traded goods in the local currency of country $i$ in state $s$. For this economy with flexible exchange rates, note that even if $\tau_{N}^{i}(s)$ is restricted to zero, the first-order condition (5) implies

$$
\frac{R^{i}(s)}{R^{i}\left(s_{0}\right)}=\frac{U_{T}^{i}(s) / U_{N}^{i}(s)}{U_{T}^{i}\left(s_{0}\right) / U_{N}^{i}\left(s_{0}\right)}=P_{T}^{i}(s),
$$

where we have used the normalization $P_{T}^{i}\left(s_{0}\right)=1$. But now the right side of (70) varies with $i$ so that there are no incomplete tax constraints: allocations can be constructed ignoring this constraint, and then $P_{T}^{i}(s)$ can be chosen so that (70) holds. We summarize this discussion with a proposition. 
Proposition 3B (Portfolio Taxes to Help Policy-Restricted Countries Unnecessary with Flexible Exchange Rates) In this economy with restricted policies and flexible exchange rates, a union-wide fiscal authority concerned solely with insurance neither makes transfers nor levies portfolio taxes.

This result implies that once we allow for flexible exchange rates, there is no need to levy portfolio taxes. Propositions 3A and 3B might lead one to conjecture that, more generally, portfolio taxes are necessary only when countries belong to a monetary union and that these taxes offset cross-country externalities. We show in the next section that this conjecture is incorrect.

\subsection{Portfolio taxes without a monetary union}

Here we consider a fiscal union with flexible exchange rates and severe restrictions on the policies of national governments. Specifically, no countries have access to a payroll tax on labor or nontraded goods taxes, the Northern countries have access to portfolio taxes, whereas Southern countries do not. The union-wide authority, however, has the ability to levy portfolio taxes on any country $i$ it chooses. To make our point even starker, imagine that the price of nontraded goods is flexible rather than sticky.

Here the lack of a payroll tax means that a country no longer has an instrument to offset the monopoly distortion in the labor market. Thus, since nontraded goods prices are flexible, the price setting rule (12) reduces to

$$
P_{N}^{i}(s)=\frac{\varepsilon}{\varepsilon-1} \frac{W^{i}(s)}{A^{i}(s)},
$$

which adds an extra constraint to the national governments' problems. In particular, using the consumer first-order condition

$$
-\frac{U_{L}^{i}(s)}{U_{N}^{i}(s)}=\frac{W^{i}(s)}{P_{N}^{i}(s)},
$$

we can rewrite (71) as

$$
-\frac{U_{L}^{i}(s)}{U_{N}^{i}(s)}=\frac{\varepsilon-1}{\varepsilon} A^{i}(s) .
$$

These monopoly distortion constraints imply that the marginal rate of substitution between labor and nontraded goods is strictly lower than the marginal rate of transformation between these variables.

Now, imagine repeating our analysis for this environment. Clearly, the union-wide authority can simply levy the appropriate portfolio tax on each Southern country and achieve the same allocations as when all countries have access to and use their portfolio taxes to maximize their citizens' welfare. We summarize this discussion with the following proposition.

Proposition 4 (Portfolio Taxes to Help Policy-Restricted Countries with Flexible Exchange Rates) In this economy with restricted policies and flexible exchange rates, 
a union-wide fiscal authority concerned solely with insurance is necessary only to levy the portfolio taxes that policy-restricted countries are unable to levy.

Clearly, this proposition offers a paternalistic view of the union-wide authority: Southern countries are unable to carry out desirable policies, so the benevolent unionwide authority intervenes in their place.

\subsection{Policy with self-interested governments}

In the environments that we have so far considered, except for international transfers, the equilibrium does not depend on the tier of decision making at which policies are set. For example, if instead of allowing national governments to set their countryspecific fiscal policies, we attributed this power to the union-wide authority, then the same equilibrium would arise. We refer to this property of equilibrium as irrelevance of delegation of authority. The key assumptions that lead to this result are that the government of each country maximizes the utility of its citizens and that the union maximizes a weighted average of the utility of the consumers in each country (along with the assumption of commitment to policy and that each country is small). Here we consider self-interested governments, namely, those with objective functions that differ from those of their citizens, and show how the delegation of authority matters for the allocations that can be achieved.

We modify our complete market model as follows. Government $i$ chooses the amount of nontraded goods, $G^{i}(s)$, to devote to government spending so that the resource constraints for nontraded goods are now

$$
C_{N}^{i}(s)+G^{i}(s) \leq A^{i}(s) L^{i}(s) \text { for all } s .
$$

Consumer preferences are unchanged; in particular, consumers do not value government spending. We model a self-interested government by assuming that the preferences of the government of country $i$ are given by

$$
\sum_{s} \mu(s) W^{i}\left(C_{N}^{i}(s), G^{i}(s), C_{T}^{i}(s), L^{i}(s), s\right)
$$

The utility function $W^{i}(\cdot)$ of the government is sufficiently general so that it can capture many different types of self-interest. Here we show how equilibrium is affected by the delegation of portfolio taxes by considering two environments. In both environments, we assume that the national government of a country sets nontraded goods taxes, payroll taxes, and domestic transfers, and the union-wide authority sets international transfers. In the national delegation model, however, the national governments also set portfolio taxes, whereas in the union delegation model, the union-wide authority sets these taxes. We study these alternative delegation schemes in a complete market version of the model. 


\subsubsection{National delegation}

We start by characterizing equilibrium at the middle tier. Building on our earlier logic, given $T_{I}^{c}$ and the strategies of other governments, the problem of country $i$ reduces to

$$
\max _{\left\{C_{N}^{i}(s), G^{i}(s), C_{T}^{i}(s), L^{i}(s)\right\}} \sum_{s} \mu(s) W^{i}\left(C_{N}^{i}(s), G^{i}(s), C_{T}^{i}(s), L^{i}(s), s\right),
$$

subject to (73) and

$$
\sum_{s} Q(s) P_{T}(s) C_{T}^{i}(s) \leq \sum_{s} Q(s) P_{T}(s)\left[Y_{T}^{i}(s)+T_{I}^{i, c}\right]
$$

where the prices $P_{T}=P_{T}\left(T_{I}^{c}, \pi_{-i}\left(T_{I}^{c}\right)\right)$ and $Q=Q\left(T_{I}^{c}, \pi_{-i}\left(T_{I}^{c}\right)\right)$ are taken as given by this government. The first-order conditions for nontraded consumption, labor, and traded goods can be summarized by

$$
\begin{aligned}
& W_{N}^{i}(s)=W_{G}^{i}(s), \\
& -W_{L}^{i}(s)=A^{i}(s) W_{N}^{i}(s), \\
& \frac{\mu(s) W_{T}^{i}(s)}{\mu\left(s_{0}\right) W_{T}^{i}\left(s_{0}\right)}=Q(s) P_{T}(s),
\end{aligned}
$$

where we have used the normalization that $Q\left(s_{0}\right)=P_{T}\left(s_{0}\right)=1$. Evaluating (77) for country $i$ and country 0 gives that this constraint implies

$$
\frac{W_{T}^{i}(s)}{W_{T}^{i}\left(s_{0}\right)}=\frac{W_{T}^{0}(s)}{W_{T}^{0}\left(s_{0}\right)}
$$

The extra constraints (75), (76), and (78) should be thought of as self-interested government constraints. That is, the union-wide authority must respect the incentives of the self-interested national governments to distort allocations away from those that maximize the utility of their consumers. The union-wide authority's problem is thus

$$
\max _{\left\{C_{N}^{i}(s), G^{i}(s), C_{T}^{i}(s), L^{i}(s)\right\}} \int_{i} \lambda^{i}\left[\sum_{s} \mu(s) U^{i}\left(C_{N}^{i}(s), C_{T}^{i}(s), L^{i}(s), s\right)\right] \mathrm{d} i,
$$

subject to (73), (75), (76), (78), and

$$
\int_{i} C_{T}^{i}(s) \mathrm{d} i \leq \int_{i} Y_{T}^{i}(s) \mathrm{d} i
$$

The constraints in the union-wide authority's problem capture the union's inability to control the policies of noncooperative governments. 


\subsubsection{Union delegation}

We start by characterizing equilibrium at the middle tier. Building on our earlier logic, given $T_{I}^{c}$ and the strategies of other governments, the problem of country $i$ reduces to

$$
\max _{\left\{C_{N}^{i}(s), G^{i}(s), C_{T}^{i}(s), L^{i}(s)\right\}} \sum_{s} \mu(s) W^{i}\left(C_{N}^{i}(s), G^{i}(s), C_{T}^{i}(s), L^{i}(s), s\right),
$$

subject to $(73)$,

$$
\sum_{s} Q(s) P_{T}(s) C_{T}^{i}(s) \leq \sum_{s} Q(s) P_{T}(s)\left[Y_{T}^{i}(s)+T_{I}^{i, c}\right],
$$

and

$$
\frac{\mu(s) U_{T}^{i}(s)}{\mu\left(s_{0}\right) U_{T}^{i}\left(s_{0}\right)}=\frac{Q(s) P_{T}(s)}{1-\tau_{D}^{i}(s)} \text { for all } s \neq s_{0},
$$

where $Q(s) P_{T}(s) /\left[1-\tau_{D}^{i}(s)\right]$ is under the control of the union-wide authority, and we have used the normalizations $Q\left(s_{0}\right)=P_{T}\left(s_{0}\right)=1$ and $\tau_{D}^{i}\left(s_{0}\right)=0$.

Critically, here the union-wide authority can set portfolio taxes in a way that completely controls the first-order conditions governing traded goods consumption in each country. The value of the union-wide authority's problem here is weakly higher than under the national delegation scheme.

Proposition 5 (Union Delegation of Portfolio Taxes Preferred) In this economy with self-interested governments, the welfare of the union is higher under the union delegation scheme than under the national delegation scheme.

To prove this result, first note that the problem of a government under national delegation is equivalent to one in which we expand the choice set of the government to include $\left\{\tau_{D}^{i}(s)\right\}$ and add the consumer's first-order condition (81) as a constraint. Then, observe that in the union delegation problem, the union can always implement the allocations that arise under national delegation by choosing the same portfolio taxes as governments choose under national delegation, but can possibly do better.

\section{Nontraded goods taxes in practice}

As we have shown, when governments have access to nontraded goods taxes, there is no need to ever levy portfolio taxes under complete markets. Here we argue that, in practice, governments both have the ability to levy nontraded goods taxes and actually do so. In this precise sense, our analysis does not provide a strong justification for instituting a new regime of portfolio taxes within the European Union.

To elaborate, although free-trade agreements in currency areas typically make it very difficult to differentially tax traded goods, they usually allow some differential tax treatment of nontraded goods. For example, in May 2009 the Council of the European Commission adopted a directive (2009/47/EC) that permanently allowed 


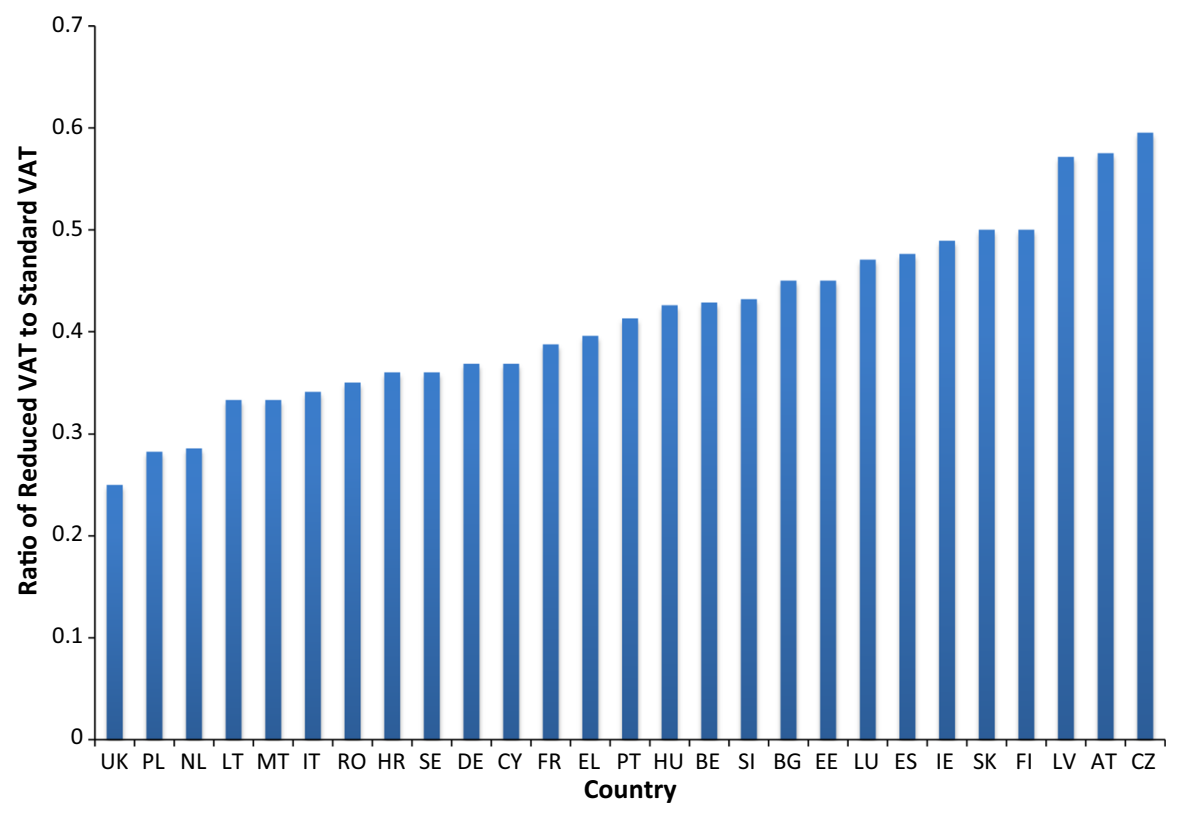

Fig. 1 Reduced VAT by country. Source: European Commission (2016)

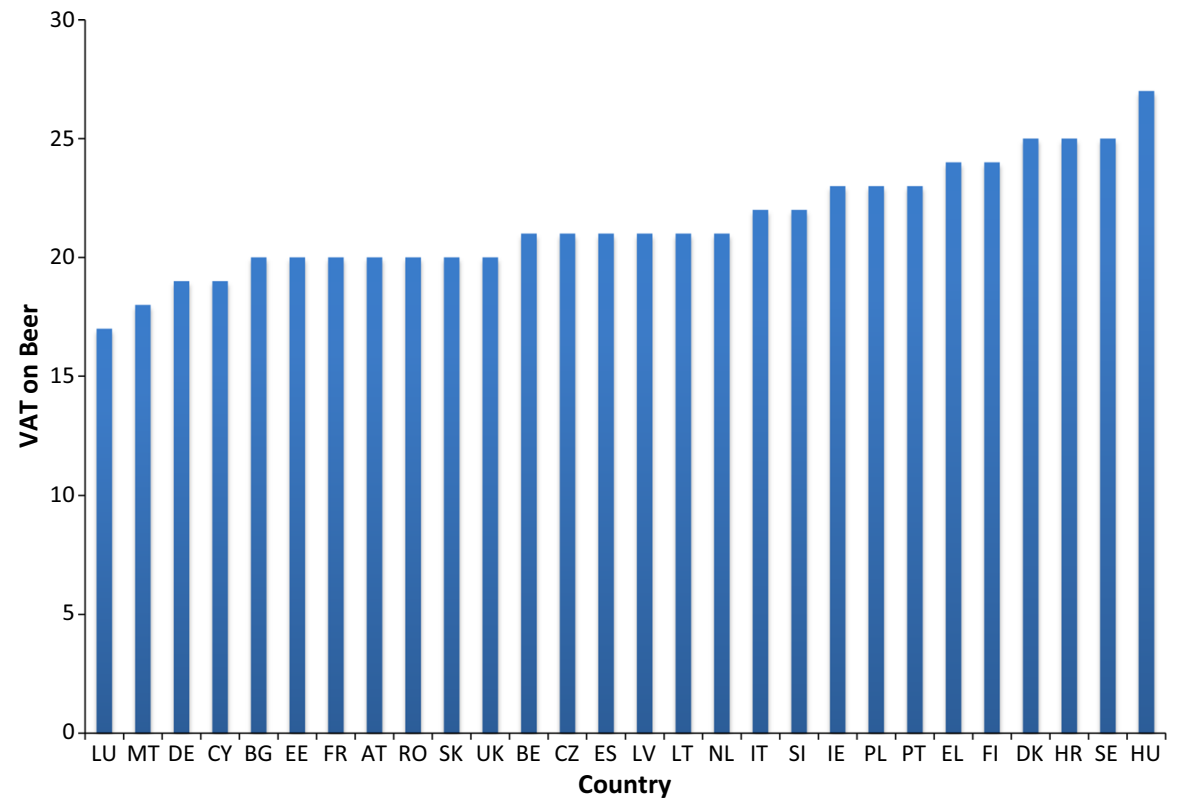

Fig. 2 VAT on beer by country. Source: European Commission (2016) 
the optional use of reduced rates for the value-added tax (VAT) on certain laborintensive local services, including restaurant services. The rationale was that for such nontraded goods, there is no risk of unfair competition between service providers in different member countries. A document of the European Commission on VAT rates (European Commission (2016)) further provides evidence of how, in practice, VAT taxes on nontraded goods (and even some traded goods) vary across member countries, as is apparent from Fig. 1, which shows, for every member country, the ratio of reduced tax rates over standard tax rates for a variety of nontraded and traded goods, based on data from the European Commission. (See European Commission (2016). Note that Directive 2006/112/EC, which Directive 2009/47/EC expanded to include labor-intensive services, allows countries to apply either one or two reduced rates. For countries with two reduced rates, we select the midpoint between these two rates to compute the ratio of the reduced tax rate over the standard tax rate.)

In addition to this varying VAT for nontraded goods, excise taxes on specific goods also vary significantly across countries in the European Union. Using beer as a case study of a specific example of an excise tax, we observe that tax rates on beer indeed differ across member countries. (See Fig. 2 for the range of actual VAT rates on beer in 2016 in the European Union.)

\section{Conclusion}

We have argued that sophisticated financial markets obviate the need for a union-wide authority to orchestrate fiscal transfers across member countries for insurance reasons. This result holds true even when national governments are subject to additional constraints on their choice of policy because of the paucity of fiscal instruments available to them. The key idea behind these results is that even with restricted fiscal instruments and noncooperative governments, no macroeconomic externality arises across countries. If the goal of a union is to transfer ex-ante wealth from one group of countries to another, however, then an activist union-wide authority is necessary to carry out such redistribution.

In terms of the optimal delegation of authority, as long as the objective of the noncooperative governments of member countries is to maximize the welfare of their citizens, we show that an irrelevance of delegation of authority result holds. That is, the equilibrium is unchanged if any of the labor taxes, nontraded goods taxes, or portfolio taxes are delegated to the national governments or the union-wide authority. If, instead, governments pursue self-interested policies, whereas the union-wide authority is benevolent, then it is typically desirable to delegate relatively more policies to the union-wide authority rather than to national governments.

Open Access This article is distributed under the terms of the Creative Commons Attribution 4.0 International License (http://creativecommons.org/licenses/by/4.0/), which permits unrestricted use, distribution, and reproduction in any medium, provided you give appropriate credit to the original author(s) and the source, provide a link to the Creative Commons license, and indicate if changes were made. 


\section{Appendix}

Here we provide details behind the derivations in the text.

Setup for Proposition $3 A$. It is convenient to substitute out traded goods prices and write the incomplete tax constraints as in (64). The union-wide problem is to solve

$$
\max _{\left\{C_{T}^{i}(s), L^{i}(s)\right\}} \int_{i} \lambda^{i}\left[\sum_{s} \mu(s) U^{i}\left(A^{i}(s) L^{i}(s), C_{T}^{i}(s), L^{i}(s), s\right)\right] \mathrm{d} i,
$$

subject to the resource constraints,

$$
\int_{i} C_{T}^{i}(s) \mathrm{d} i \leq \int_{i} Y_{T}^{i}(s) \mathrm{d} i \text { for all } s
$$

and the incomplete tax constraints,

$$
\frac{R^{0}(s)}{R^{0}\left(s_{0}\right)}-\frac{R^{i}(s)}{R^{i}\left(s_{0}\right)}=0 \quad \text { for all } i \in S \text { and } s \neq s_{0}
$$

where $\mu(s) \theta(s)$ and $\mu(s) \eta^{i}(s)$ are the normalized multipliers on the resource constraints and the incomplete tax constraints. The first-order conditions for $C_{T}^{i}(s)$ for $i \in N$ are

$$
\lambda^{i} U_{T}^{i}(s)=\theta(s)
$$

The first-order conditions for $L^{i}(s)$ for $i \in N$ are

$$
A^{i}(s) U_{N}^{i}(s)+U_{L}^{i}(s)=0 .
$$

The first-order conditions for $C_{T}^{i}(s)$ for $i \in S$ with $i \neq 0$ and $s \neq s_{0}$ are

$$
\lambda^{i} U_{T}^{i}(s)+\phi^{i}(s)=\theta(s),
$$

where $\eta^{i}\left(s_{0}\right)=0$ and $\phi^{i}(s)$ is defined as

$$
\phi^{i}(s)=-\eta^{i}(s) \frac{\partial R^{i}(s) / \partial C_{T}^{i}(s)}{R^{i}\left(s_{0}\right)} .
$$

The first-order condition for $C_{T}^{i}\left(s_{0}\right)$ for $i \in S$ with $i \neq 0$ has the form of (84) with

$$
\phi^{i}\left(s_{0}\right)=-\frac{\partial\left(1 / R^{i}\left(s_{0}\right)\right)}{\partial C_{T}^{i}\left(s_{0}\right)} \sum_{s \neq s_{0}} \frac{\mu(s)}{\mu\left(s_{0}\right)} \eta^{i}(s) R^{i}(s) .
$$

The first-order conditions for $C_{T}^{0}(s)$ and $s \neq s_{0}$ have the form of (84) with

$$
\phi^{0}(s)=\frac{1}{R^{0}\left(s_{0}\right)} \frac{\partial R^{0}(s)}{\partial C_{T}^{0}(s)} \int_{j \in S} \eta^{j}(s) \mathrm{d} j
$$


whereas the first-order condition for $C_{T}^{0}\left(s_{0}\right)$ has the form of (84) with

$$
\phi^{0}\left(s_{0}\right)=\frac{\partial\left(1 / R^{0}\left(s_{0}\right)\right)}{\partial C_{T}^{0}\left(s_{0}\right)} \sum_{s \neq s_{0}}\left[\frac{\mu(s)}{\mu\left(s_{0}\right)} R^{0}(s) \int_{j \in S} \eta^{j}(s) \mathrm{d} j\right],
$$

where $\eta^{0}(s)=0$ for all $s$. Let $H^{i}(s) \equiv \lambda^{i}\left[A^{i}(s) U_{N}^{i}(s)+U_{L}^{i}(s)\right]$ be the Paretoweighted value of the net marginal utility of supplying one more unit of time as labor in the nontraded goods sector. The first-order condition for $L^{i}(s)$ for $i \in S$ with $i \neq 0$ and $s \neq s_{0}$ is

$$
H^{i}(s)=\eta^{i}(s) \frac{\partial R^{i}(s) / \partial L^{i}(s)}{R^{i}\left(s_{0}\right)},
$$

so that solving for $\eta^{i}(s)$ for $i \neq 0$ and $s \neq s_{0}$ gives

$$
\eta^{i}(s)=\frac{H^{i}(s) R^{i}\left(s_{0}\right)}{\partial R^{i}(s) / \partial L^{i}(s)} .
$$

Substituting for $\eta^{i}(s)$ into the various expressions for $\phi^{i}(s)$ allows us to express $\phi^{i}(s)$ directly in terms of allocations. For example, substituting (90) into (85), and using the definition of $H^{i}(s)$, gives

$$
\phi^{m}(s)=-\lambda^{m}\left[A^{m}(s) U_{N}^{m}(s)+U_{L}^{m}(s)\right] \frac{\partial R^{m}(s) / \partial C_{T}^{m}(s)}{\partial R^{m}(s) / \partial L^{m}(s)},
$$

which is expression (67) in the text.

To show how the first-order conditions for risk sharing can be decentralized, consider the competitive equilibrium. The consumer's problem is

$$
\max _{\left\{C_{N}^{i}(s), C_{T}^{i}(s), L^{i}(s), D^{i}(s)\right\}} \sum_{s} \mu(s) U^{i}\left(C_{N}^{i}(s), C_{T}^{i}(s), L^{i}(s), s\right)
$$

subject to

$$
\sum_{s} Q(s) D^{i}(s) \leq 0
$$

and a budget constraint for each state $s$,

$$
\begin{aligned}
& {\left[1+\tau_{N}^{i}(s)\right] P_{N}^{i} C_{N}^{i}(s)+P_{T}(s) C_{T}^{i}(s) \leq W^{i}(s) L^{i}(s)} \\
& \quad+P_{T}(s)\left[Y_{T}^{i}(s)+T^{i}(s)+T_{I}^{i}(s)\right]+\Pi^{i}(s)+\left[1-\tau_{D}^{i}(s)\right] D^{i}(s) .
\end{aligned}
$$

Letting $\rho^{i}$ be the multiplier on the asset market constraint and $\mu(s) \alpha^{i}(s)$ be the normalized multiplier on the budget constraint, the first-order conditions for $C_{T}^{i}(s), D^{i}(s)$, 
$L^{i}(s)$, and $C_{N}^{i}(s)$ are

$$
\begin{aligned}
& U_{T}^{i}(s)=\alpha^{i}(s) P_{T}(s), \\
& \rho^{i} Q(s)=\alpha^{i}(s) \mu(s)\left[1-\tau_{D}^{i}(s)\right], \\
& -U_{L}^{i}(s)=\alpha^{i}(s) W^{i}(s), \\
& U_{N}^{i}(s)=\alpha^{i}(s)\left[1+\tau_{N}^{i}(s)\right] P_{N}^{i} .
\end{aligned}
$$

We can manipulate these conditions to obtain

$$
\frac{U_{T}^{i}(s)\left[1-\tau_{D}^{i}(s)\right]}{\rho^{i}}=\frac{U_{T}^{j}(s)\left[1-\tau_{D}^{j}(s)\right]}{\rho^{j}} .
$$

Suppose that we are given the allocations from the union-wide problem with weights $\lambda^{i}$ and multipliers $\phi^{i}(s)$. If we set $\lambda^{i}=1 / \rho^{i}$ and

$$
\tau_{D}^{i}(s)=-\frac{\rho^{i} \phi^{i}(s)}{U_{T}^{i}(s)} \text { for } i \in S \quad \text { and } \tau_{D}^{i}(s)=0 \text { for } i \in N
$$

then the risk-sharing first-order conditions in the union-wide problem and the competitive equilibrium coincide.

\section{References}

Aguiar, M., Amador, M., Farhi, E., Gopinath, G.: Crisis and commitment: inflation credibility and the vulnerability to sovereign debt crises. Mimeo, Harvard University (2013)

Chari, V.V., Kehoe, P.J.: On the need for fiscal constraints in a monetary union. J. Monet. Econ. 54, 23992408 (2007)

Chari, V.V., Kehoe, P.J.: Time inconsistency and free-riding in a monetary union. J. Money Credit Bank. 40, 1329-1356 (2008)

European Commission: VAT rates applied in the member states of the European Union (2016). http://ec.europa.eu/taxation_customs/sites/taxation/files/resources/documents/taxation/vat/ how_vat_works/rates/vat_rates_en.pdf

Farhi, E., Werning, I.: Fiscal unions. Mimeo, MIT (2013)

Gali, J., Monacelli, T.: Monetary policy and exchange rate volatility in a small open economy. Rev. Econ. Stud. 72, 707-734 (2005)

Gali, J., Monacelli, T.: Optimal monetary and fiscal policy in a currency union. J. Int. Econ. 76, 116-132 (2008)

Kenen, P.: The theory of optimum currency areas: an eclectic view. In: Mundell, R.A., Swoboda, A.K. (eds.) Monetary Problems of the International Economy. Chicago University Press, Chicago (1969)

Mundell, R.: The economics of common currencies. In: Johnson, H.G., Swoboda, A.K. (eds.) Uncommon Arguments for Common Currencies. Allen and Unwin, London (1973)

Obstfeld, M., Rogoff, K.: Exchange rate dynamics redux. J. Polit. Econ. 103, 624-660 (1995) 